\title{
ENSO's Impact on the Gap Wind Regions of the Eastern Tropical Pacific Ocean*
}

\author{
Michael A. AleXANDER \\ NOAA/Earth System Research Laboratory, Boulder, Colorado \\ HYODAE SEO \\ Woods Hole Oceanographic Institution, Woods Hole, Massachusetts \\ SHANG PING XIE \\ International Pacific Research Center, and the Department of Meteorology, University of Hawaii at Manoa, Honolulu, Hawaii \\ JAMES D. SCOTT \\ Cooperative Institute for Research in Environmental Sciences, University of Colorado, and NOAA/Earth System \\ Research Laboratory, Boulder, Colorado
}

(Manuscript received 15 June 2011, in final form 4 November 2011)

\begin{abstract}
The recently released NCEP Climate Forecast System Reanalysis (CFSR) is used to examine the response to ENSO in the northeast tropical Pacific Ocean (NETP) during 1979-2009. The normally cool Pacific sea surface temperatures (SSTs) associated with wind jets through the gaps in the Central American mountains at Tehuantepec, Papagayo, and Panama are substantially warmer (colder) than the surrounding ocean during El Niño (La Niña) events. Ocean dynamics generate the ENSO-related SST anomalies in the gap wind regions as the surface fluxes damp the SSTs anomalies, while the Ekman heat transport is generally in quadrature with the anomalies. The ENSO-driven warming is associated with large-scale deepening of the thermocline; with the cold thermocline water at greater depths during El Niño in the NETP, it is less likely to be vertically mixed to the surface, particularly in the gap wind regions where the thermocline is normally very close to the surface. The thermocline deepening is enhanced to the south of the Costa Rica Dome in the Papagayo region, which contributes to the local ENSO-driven SST anomalies. The NETP thermocline changes are due to coastal Kelvin waves that initiate westward-propagating Rossby waves, and possibly ocean eddies, rather than by local Ekman pumping. These findings were confirmed with regional ocean model experiments: only integrations that included interannually varying ocean boundary conditions were able to simulate the thermocline deepening and localized warming in the NETP during El Niño events; the simulation with variable surface fluxes, but boundary conditions that repeated the seasonal cycle, did not.
\end{abstract}

\section{Introduction}

The ocean temperatures and circulation in the northeastern tropical Pacific Ocean (NETP), taken here to be

\footnotetext{
* Supplemental information related to this paper is available at the Journals Online website: http://dx.doi.org/10.1175/JCLI-D11-00320.s1.

Corresponding author address: Michael Alexander, NOAA/Earth System Research Laboratory, R/PSD1, 325 Broadway, Boulder, CO 80305.

E-mail: michael.alexander@noaa.gov
}

$5^{\circ}-18^{\circ} \mathrm{N}, 110^{\circ} \mathrm{W}$ to the American coast, are complex and influenced by many factors. The topography of Central America strongly affects the regional atmospheric circulation and underlying ocean in the NETP. Three major gaps in the $\sim 1-\mathrm{km}$-high Sierra Madre, located at the Isthmus of Tehuantepec, at the Nicaragua-Costa Rica border, and in central Panama, funnel low-level jets from eastern North America and the Caribbean Sea into the NETP. Northerly winds associated with midlatitude storms intermittently pulse through the mountains and then over the Gulf of Tehuantepec (TT) during winter, while easterly trade winds flow through the two southern gaps and continue over the Gulfs of Papagayo (PP) and 
Panama (PN; e.g., see Steenburgh et al. 1998; Chelton et al. 2000). The winds over TT can reach $30 \mathrm{~m} \mathrm{~s}^{-1}$, and after leaving the coast, air trajectories follow anticyclonic arcs, as an inertial flow nearly free of pressure gradient force (Clarke 1988) that may also be influenced by the penetration of relatively cold dense Atlantic air into the Pacific (Steenburgh et al. 1998), while the more steady trade winds flow through the Papagayo and Panama gaps. The gap winds also vary with the seasonal cycle: the strongest jets and greatest impact on the NETP occur during boreal winter (Xie et al. 2005; Sun and Yu 2006; Romero-Centeno et al. 2007).

Local centers of surface wind stress associated with the gap wind jets create mesoscale structures in the SST and thermocline in the NETP. Cyclonic wind stress curl generates upwelling in the eastern Gulf of Tehuantepec, while anticyclonic wind stress curl deepens the thermocline farther west creating the Tehuantepec bowl (Kessler 2006). Strong wind-driven mixing cools the SST in the all three gap wind regions, but especially in the Gulf of Tehuatepec during winter (Liang et al. 2009; McCreary et al. 1989; Sun and Yu 2006). Because of the orientation of the mountain gaps at Papagayo, the jet and associated wind curl forcing is more zonal compared with the gap and jet at Tehuantepec. In addition, the positive curl on the southern flank of the Papagayo jet is enhanced by the winds flowing into the ITCZ, curving from south to east after crossing the equator east of $\sim 95^{\circ} \mathrm{E}$ (Kessler 2002). As a result, there is not compensating downward Ekman pumping directly west of the upward forcing and the strong cyclonic wind stress generates upwelling ocean Rossby waves that propagate westward into the Pacific creating the Costa Rica Dome between $85^{\circ}$ and $90^{\circ} \mathrm{W}$ at $\sim 9^{\circ} \mathrm{N}$ (Hoffman et al. 1981; McCreary et al. 1989; Kessler 2002, 2006; Xie et al. 2005). Upwelling within the Costa Rica Dome brings the cold, nutrient-rich water in the thermocline very close to the surface, supporting a complex food web (Fiedler 2002). A dipole in the mean wind curl, with upwelling favorable winds near the coast acts to cool the ocean in the Panama Bight (Kessler 2002, 2006).

Several major current systems flow through the NETP, including the westward North and South Equatorial Currents (NEC and SEC, respectively) along the edges of the domain and the eastward North Equatorial Counter Current (NECC) at $\sim 7^{\circ} \mathrm{N}$. Based on a detailed analysis of the subsurface temperature data and surface winds, Kessler $(2002,2006)$ concluded that a substantial portion of the NECC divides and flows westward into the NEC and SEC $\sim 2000 \mathrm{mi}(1 \mathrm{mi} \approx 1.6 \mathrm{~km})$ from the Central American coast, while the upper ocean east of $115^{\circ} \mathrm{W}$ has a different circulation regime driven by the regional winds. A portion of the cold water that local winds cause to upwell in the Costa Rica Dome is supplied by the eastward "Tsuchia jet," which is located at about $150-\mathrm{m}$ depth and $6^{\circ} \mathrm{N}$ in the eastern Pacific (Rowe et al. 2000; Kessler 2002; Furue et al. 2009). While wind-driven linear ocean dynamics appears to explain much of the mean annual cycle of the upper-ocean circulation in the NETP, nonlinear eddies generated by strong currents near the coast may also contribute to the seasonal evolution of the Costa Rica Dome (Umatani and Yamagata 1991).

Both atmospheric and oceanic changes associated with El Niño-Southern Oscillation (ENSO) strongly influence the climate across the tropical Pacific including the NETP region. During El Niño events, positive SST anomalies develop along the equator and the west coast of the Americas, generally beginning in boreal spring/summer and then amplifying through the following winter. The intertropical convergence zone, shifts toward the equator, resulting in increased precipitation and anomalous northeasterly winds from approximately $1^{\circ}$ to $10^{\circ} \mathrm{N}$ over the eastern Pacific (e.g., Rasmusson and Carpenter 1982; Harrison and Larkin 1998). The anomalies are generally opposite for La Niña events, although there are some nonlinearities in the evolution of warm and cold events (e.g., Larkin and Harrison 2002; McPhadden and Zhang 2009; Okumura and Deser 2010). The equatorial thermocline variability associated with ENSO excites Kelvin and other coastally trapped ocean waves, which propagate poleward along the eastern Pacific boundary generating substantial SST, sea level, and thermocline anomalies (Enfield and Allen 1980; Chelton and Davis 1982; Clarke and van Gorder 1994). The zonal extent of these waves decreases with latitude and their direct impact on the ocean is on the order of $100 \mathrm{~km}$ of shore in the NETP (e.g., Chelton et al. 1998). Energy from the coastal waves, however, can also be refracted as long Rossby waves that propagate westward across the extratropical Pacific where they can influence the depth of the thermocline (e.g., White 1977; Schopf et al. 1981; Fu and Qiu 2002).

Over the past decade, there have been a few studies of the influence of ENSO on the Central American gap winds and the surrounding oceans. Romero-Centeno et al. (2003) used wind observations from the southern edge of the Isthmus of Tehuantepec to construct a statistical model of the Tehuantepec gap wind speed and determined that the mean wind speed and the occurrence of northerly winds are greater at the Isthmus of Tehuantepec during El Niño relative to La Niña years. In contrast, using $1^{\circ} \times 1^{\circ}$ gridded data, Karnauskas et al. (2008) found that ENSO does not influence the winds at Tehuantepec, but does affect the winds and SSTs in the Gulf of Papagayo, which warms more than the surrounding NETP during El Niño events. Finescale data 
CFSR 5m Temp (anom shaded, total contour)
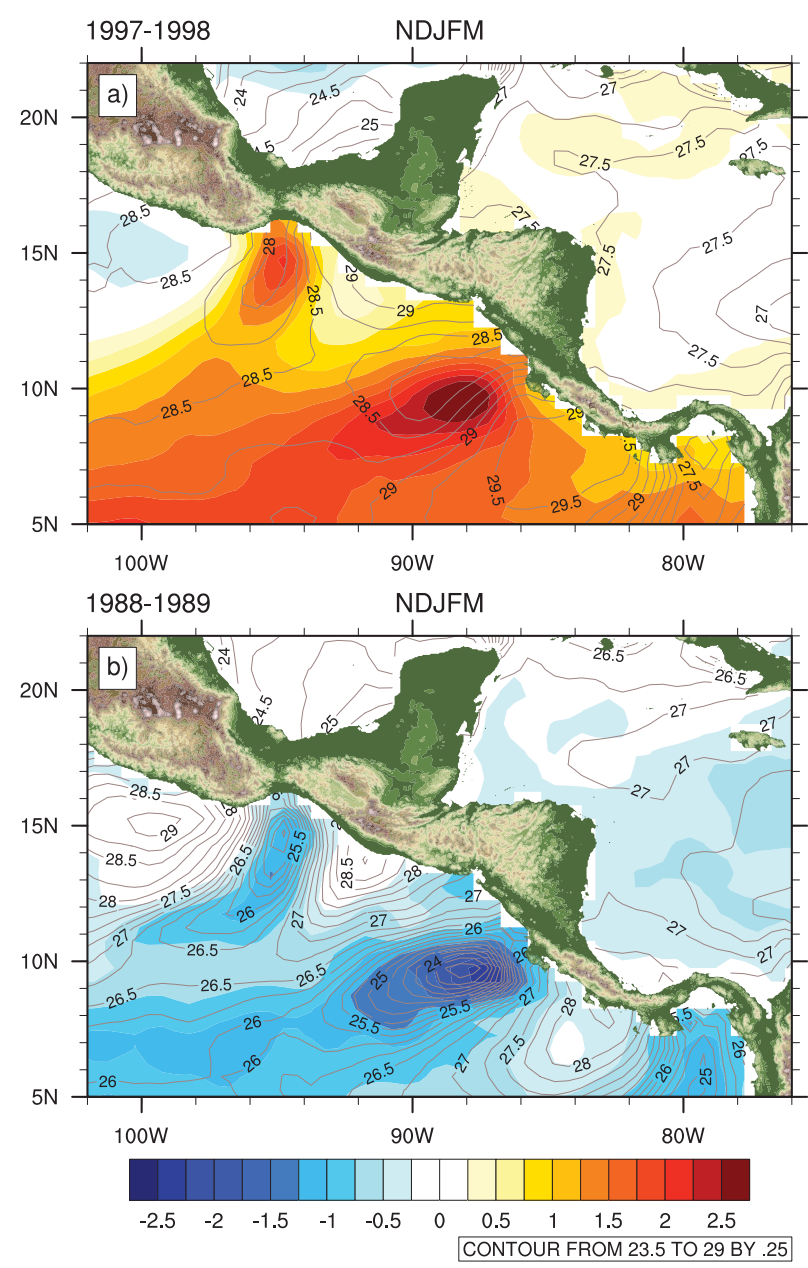

FIG. 1. (a) The SST (contours) and SST departure from the 19792009 mean (shading) during NDJFM for (a) the 1997/98 El Niño event and (b) the 1988/89 La Niña event. The data are from the 5-m ocean temperature in the NCEP CFSR for the years 1979-2009. The contour and shading intervals are both $0.25^{\circ} \mathrm{C}$.

indicates that large positive SST anomalies occurred in all three gap wind regions during the 1997/98 El Niño and 1988/89 La Niña event (Fig. 1), particularly near the Costa Rica Dome.

We investigate ENSO-driven regional features in the NETP by using high-resolution observations over an extended period of time in conjunction with eddy-resolving ocean model experiments. While high-resolution satellite data have been used to study this region (e.g., Chelton et al. 2000; Xie et al. 2005) they have been limited to short periods since the late 1990s and have not addressed interannual variability. A high-resolution $\left(1 / 4^{\circ}\right)$ SST product has recently become available (Reynolds et al. 2007) as has the Climate Forecast System Reanalysis (CFSR), with a nominal resolution of $\sim 40 \mathrm{~km}$. By using recent high-resolution datasets we hope to better resolve the extent to which ENSO modulates the gap winds and the underlying ocean, and gain a more thorough understanding of the processes involved including air-sea interactions and ocean dynamics. We will also address these issues using a regional ocean model, since previous studies have shown that they are able to reproduce the mean seasonal state of the NETP reasonably well (Umatani and Yamagata 1991; Sun and Yu 2006; Seo et al. 2007). The data and model used here are described in section 2, the results from the observational analyses and model experiments are presented in section 3, and the summary and conclusions are presented in section 4 .

\section{Data and methods}

\section{a. Data}

The primary source for the atmosphere and ocean fields used here is the CFSR (Saha et al. 2010) from the National Centers for Environmental Prediction (NCEP). The CFSR is global and includes models of the atmosphere, ocean, land surface, and sea ice and an assimilation system to merge the model first-guess fields with observations. The resolution of the spectral atmospheric model is T382 $(\sim 38 \mathrm{~km})$ with 64 vertical levels. The ocean component of CFSR, the Modular Ocean Model (MOM, version 4), has a constant zonal resolution of $0.5^{\circ}$ longitude, but a variable meridional resolution that increases from $0.25^{\circ}$ between $10^{\circ} \mathrm{N}$ and $10^{\circ} \mathrm{S}$ to $0.5^{\circ}$ at $30^{\circ}$ latitude, and remains constant from there to the Poles. The MOM output has been archived on a $0.5^{\circ}$ latitude $\times$ $0.5^{\circ}$ longitude grid. There are 40 vertical levels with 27 in the upper $400 \mathrm{~m}$. Preliminary analyses indicate that the CFSR output is superior to previous NCEP reanalyses although some biases remain (Higgins et al. 2010; Saha et al. 2010).

The CFSR was initially generated for the years 19792009 , which is the period used here. A wide array of observations are assimilated into the CFSR component models, key for this study are the inclusion of highresolution satellite estimates of wind speed from microwave sounders, wind stress values from scatterometers, and SST values from infrared sounders and scanning radiometers. SSTs in MOM are relaxed toward the daily NOAA high-resolution $\left(1 / 4^{\circ}\right)$ SST data (Reynolds et al. 2007). We also examine regionally averaged values from the Hadley Center Sea Ice and SST, version 1 (HadISST1; Rayner et al. 2003), available on a $1^{\circ} \times 1^{\circ}$ grid during 1950-2010 to obtain a longer SST record.

\section{b. Regional ocean model}

The ENSO-related anomalies in the NETP are also investigated using the Regional Ocean Modeling System 
(ROMS), an eddy-resolving primitive equation ocean model described by Haidvogel et al. (2000) and Shchepetkin and McWilliams (2005). The formulations used in this study include the third-order upstream horizontal advection scheme with implicit diffusivity (Shchepetkin and McWilliams 1998), supplemented with additional explicit diffusivity and diffusion, and the $K$-profile vertical mixing scheme (Large et al. 1994). The ocean domain covers the eastern tropical Pacific Ocean, from $5^{\circ} \mathrm{S}$ to $22^{\circ} \mathrm{N}$, extending from the west coast of the Americas to $140^{\circ} \mathrm{W}$. The model has an average horizontal resolution of $0.2^{\circ}$ latitude $\times 0.2^{\circ}$ longitude, with 30 vertical layers. The initial and boundary conditions for temperature $T$ and salinity $S$ are obtained from the monthly Simple Ocean Data Analysis (SODA; Carton et al. 2000; Carton and Giese 2008). The ocean general circulation model used in SODA (version 2.2.4) has an average horizontal resolution of $0.25^{\circ}$ latitude $\times 0.4^{\circ}$ longitude with 40 vertical levels. Several versions of SODA (v2.0.2, v2.0.4, and v2.2.4) are merged to make a continuous time series of $T / S$ to extend the period of the ROMS simulations from 1979 to 2009 . The $T$ and $S$ values are used to compute the currents at the initial time and along the boundaries, where the off-equatorial currents are calculated assuming geostrophy, while the currents within $2^{\circ}$ of the equator are obtained by linear interpolation between the off-equatorial values. We used SODA instead of CFSR, as the upper-ocean temperature in CFSR is strongly restored to the daily SST, while salinity is restored toward the monthly climatology, which can lead to large imbalances in the density field and the subsequent generation of spurious currents.

The daily averaged surface forcing used in the ROMS simulations is derived from the CFSR reanalysis. The surface wind stress is computed from the CFSR $10-\mathrm{m}$ wind $\left(U_{10}\right)$ and wind speed using a constant drag coefficient of $1.3 \times 10^{-3}$, so that the winds prescribed in the three simulations described in section $3 \mathrm{c}$ have the same wind stress. Precipitation, net shortwave, and downwelling longwave radiation fluxes are prescribed, while the upward longwave radiation is computed based on the simulated SST. The latent heat $Q_{\mathrm{lh}}$ and sensible heat $Q_{\mathrm{sh}}$ fluxes are computed using the differences $\Delta$ between air temperature at $2 \mathrm{~m} T_{a}$ and the SST, and the specific humidity of air at $2 \mathrm{~m} q_{a}$ and the saturation specific humidity at the sea surface $q_{s}$ obtained from CFSR. The $\Delta q=q_{s}-q_{a}$, and $\Delta T=\mathrm{SST}-T_{a}$ values are then prescribed in the bulk formula: $Q_{\mathrm{lh}}=\rho_{a} L_{\mathrm{va}} C_{E} \Delta q U_{10}$ and $Q_{\mathrm{sh}}=\rho_{a} C_{p a} C_{H} \Delta T U_{10}$, where $C_{E}$ and $C_{H}$ the exchange coefficients for the latent and sensible heat flux are calculated using the formulation of Fairall et al. (1996); and $\rho_{a}, C_{p a}$, and $L_{\mathrm{va}}$ are the density of air, heat capacity of air, and latent heat of vaporization, respectively. Prescribing
$\Delta q$ and $\Delta T$ poses less constraint on the simulated SSTs compared with prescribing $T_{a}$ and $q_{a}$ and using the model's SST in the bulk formula. The latter implicitly acts to restore the simulated SSTs toward the prescribed $T_{a}$, which can force the model to obtain the correct SST regardless of its actual skill (e.g., Seager et al. 1995). By using $\Delta q$ and $\Delta T$, we can avoid both explicit and implicit surface restoring.

\section{c. ENSO definition}

We examine the climatological mean and ENSO variability during boreal winter (November-March) over the period 1979-2009 for CFSR and the ROMS model experiments. The El Niño (1982, 1987, 1991, 1997, 2002, 2004, and 2006) and La Niña (1988, 1998, 1999, and 2007) years were chosen based on the NCEP definition of an event [i.e., when the magnitude of SST anomalies in the Niño-3.4 region $\left(5^{\circ} \mathrm{N}-5^{\circ} \mathrm{S}, 120^{\circ}-170^{\circ} \mathrm{W}\right)$ exceeds $0.5^{\circ} \mathrm{C}$ for 5 months]. These years, which include when the event peaked, are termed $\operatorname{yr}(0)$, and the following year is designated as $\operatorname{yr}(1)$.

\section{Results}

\section{a. SST and surface winds}

The climatological and El Niño minus La Niña composite SSTs from CFSR (taken as the 5-m ocean temperature) in the eastern tropical Pacific and the western Gulf of Mexico along with the topography of Central America are shown in Fig. 2a. As in previous studies, the climatological SSTs (contours) exhibit distinct minima near the Gulfs of Tehuantepec, Papagayo, and Panama that are several degrees cooler than the surrounding waters. The SST minima extend several hundred kilometers offshore beginning near the coast in TT and PN, but roughly $100 \mathrm{~km}$ offshore in the vicinity of PP. The composite ENSO difference (also referred to here as anomalies) indicates warming throughout the NETP during Nov(0)-Mar(1), but with much larger SST anomalies aligned with the relatively cold climatological SSTs at Tehuantepec and to the southeast of the climatological minima at Papagayo. While above normal, the ENSOrelated SST anomalies are not as strong near Panama.

In the TT, PP, and PN regions (rectangles in Fig. 2a), both the climatological SSTs and ENSO anomalies evolve with the seasonal cycle. The climatological SSTs decrease in fall and are coolest in mid- to late winter, while the SST anomalies increase through fall of $\operatorname{yr}(0)$ (Fig. 2b). In the TT and PN regions the SST anomalies decline slightly in midwinter with a secondary maxima in the spring of yr(1), while in PP they continue to grow through the winter reaching $\sim 2^{\circ} \mathrm{C}$ in $\operatorname{Mar}(1)$. 


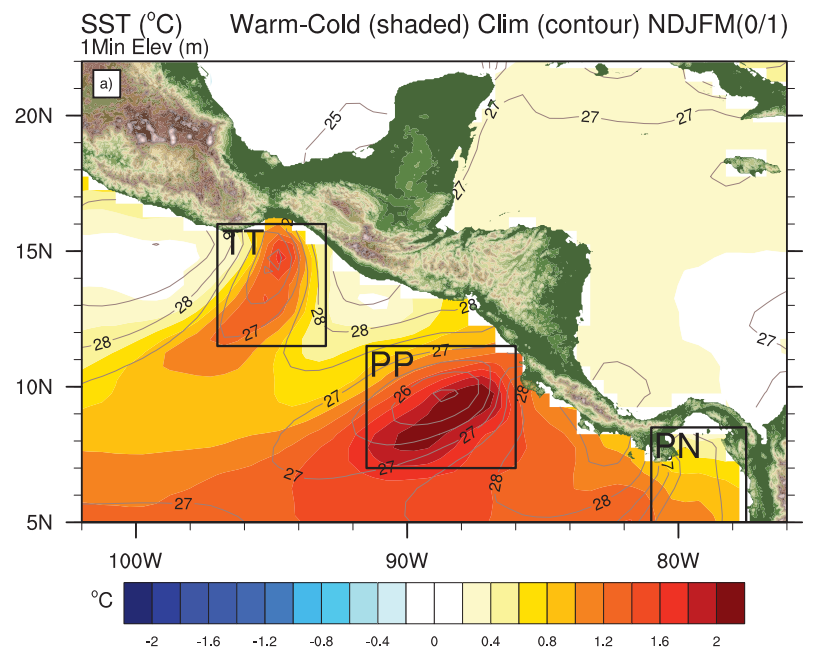

(m)

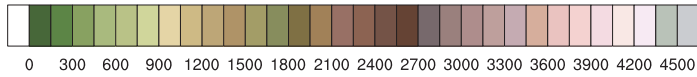
CFSR SST (1979-2009)

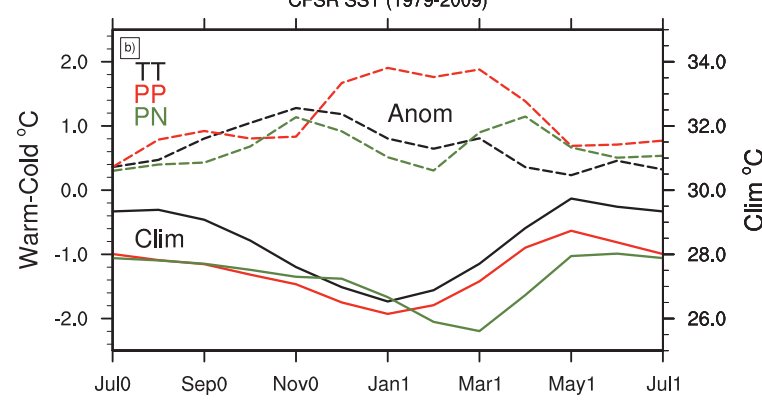

FIG. 2. (a) Climatological mean (contours) and El Niño-La Niña composite (shading, top color bar) SST during NDJFM. The contour (shading) are $0.5\left(0.2^{\circ} \mathrm{C}\right)$. Elevation over land (m, bottom color bar) and boxes that denote the Tuahantepec (TT; $11.5^{\circ}-16^{\circ} \mathrm{N}, 97^{\circ}-93^{\circ} \mathrm{W}$ ), Papagayo (PP; $\left.7^{\circ}-11.5^{\circ} \mathrm{N}, 92^{\circ}-86^{\circ} \mathrm{W}\right)$, and Panama $\left(\mathrm{PN} ; 5^{\circ}-8.5^{\circ} \mathrm{N}\right.$, $81^{\circ}-77.5^{\circ} \mathrm{W}$ ) regions are shown. (b) SST evolution of the mean (solid lines, scale on the right) and El Niño-La Niña composite (dashed lines, scale on the left) from July(0) to July(1) in the TT (black), PP (red), and PN (green) regions shown in (a). The data are from CFSR.

Maps of the SST departures relative to climatology separately for El Niño and La Niña are nearly equal and opposite in the NETP as are the seasonal evolutions of the anomalies in the three gap wind regions (see Fig. S1 in the supplemental material). We explore the ENSO response further via a scatterplot of the NovemberMarch SST departures from climatology in the three gap wind regions versus those in the Niño-3.4 region using the HadISST data over the 1950-2010 period (Fig. 3). The limited scatter about a straight line in all three regions suggest that a linear relationship with ENSO is a reasonable approximation with correlations values of $0.73,0.88$, and 0.76 between SST anomalies in Niño-3.4 with those in TT, PP, and PN, respectively. As with the CSFR analysis, the SST response is greatest in PP, but in

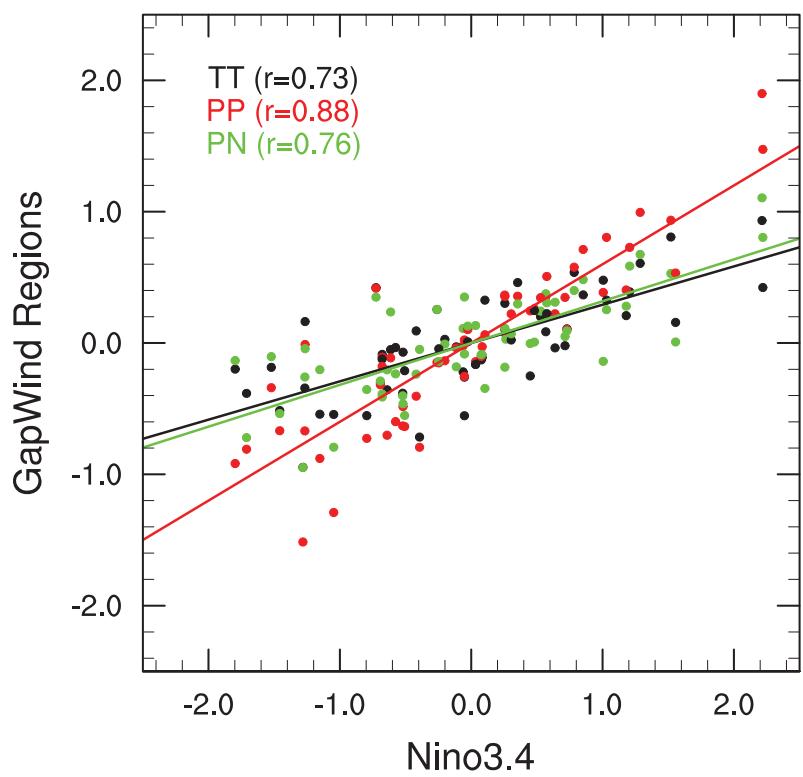

FIG. 3. Scatterplot of the SST anomalies (relative to the mean) in the Niño-3.4 region $\left(5^{\circ} \mathrm{N}-5^{\circ} \mathrm{S}, 170^{\circ}-120^{\circ} \mathrm{W}\right)$ vs those in the TT (black), PP (red), and PN (green) regions in NDJFM. The correlation between the Niño-3.4 SST anomalies and those in the TT, $\mathrm{PP}$, and $\mathrm{PN}$ regions is $0.73,0.88$, and 0.76 , respectively. The values in this figure are based on the HadISST dataset on a $1^{\circ} \times 1^{\circ}$ grid for the period $1950-2010$.

HadISST the response in $\mathrm{PN}$ is stronger and comparable to that in TT. Several factors may influence the magnitude of the regional SST anomalies, including the period of record, the data sources used, and their inherent resolution; physical processes that may lead to differences in the gap wind SST anomalies are discussed in the following sections.

Consistent with previous studies, the climatological northeast trade winds over the Gulf of Mexico extend through the mountain gaps of Central America and then hundreds of kilometers offshore over the eastern Pacific (Fig. 4a). While the wind speed is greatly reduced in the lee of the mountains, the mean winds exceed $6 \mathrm{~m} \mathrm{~s}^{-1}$ west of the three gaps, and reach $8 \mathrm{~m} \mathrm{~s}^{-1}$ over TT and $\mathrm{PP}$, more than twice as strong as in the nongap regions of the NETP. These strong winds cool the underlying SSTs (also shown in Fig. 4a) via several processes as discussed in section $3 \mathrm{~b}$.

The ENSO wind signal is quite different in the Atlantic and Pacific portions of the domain with southerly anomalies over the Caribbean and westerly to northwesterly winds over the Bay of Campeche (north of Tehuantepec), but easterly to northeasterly winds over the northeast tropical Pacific (Fig. 4b). The different wind regimes over the Caribbean and NETP basins may result from changes in precipitation over Central America and the associated near-surface outflow, as well by the Sierra 


\section{CFSR Windspeed/SST 1979-2009}
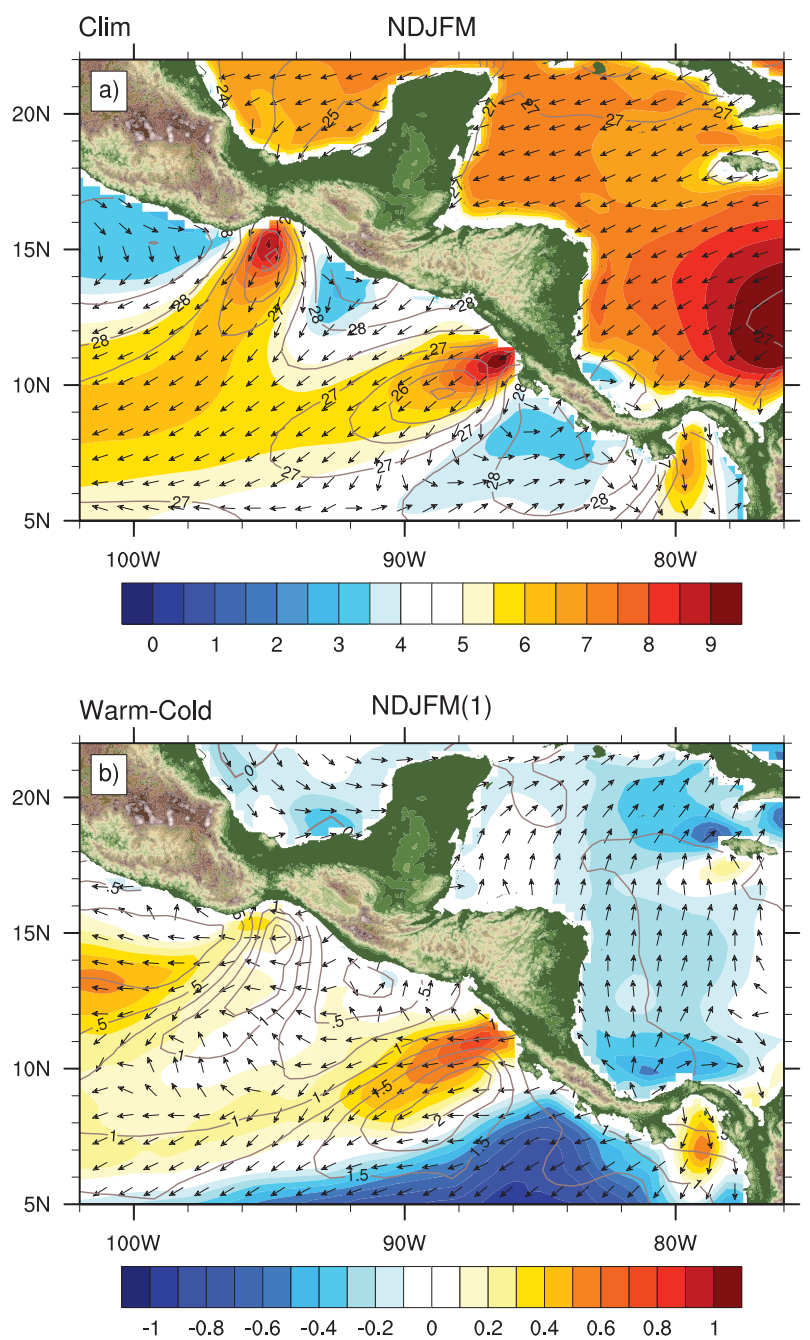

FIG. 4. (a) Mean and (b) El Niño-La Niña composite SST (contours), vector wind direction (arrows), and wind speed (shaded), during NDJFM. The contour (shading) intervals are $0.5^{\circ} \mathrm{C}$ $\left(0.5 \mathrm{~m} \mathrm{~s}^{-1}\right)$ for (a) and $0.25^{\circ} \mathrm{C}\left(0.1 \mathrm{~m} \mathrm{~s}^{-1}\right)$ for (b). Data are from CFSR.

Madre blocking the interaction between the low-level ENSO-driven circulations in the two basins. The anomalous wind changes in the NETP are part of a large-scale circulation during El Niño events as the ITCZ moves closer to the equator and the northeast trades extend farther south. The anomalous winds oppose the mean flow reducing the wind speed in a triangular shaped area with the apex at $\sim 9^{\circ} \mathrm{N}, 84^{\circ} \mathrm{W}$ and sides extending to the southern edge of the domain at $5^{\circ} \mathrm{N}$ between $82^{\circ}$ and $92^{\circ} \mathrm{W}$. The largest positive wind anomalies are generally located to the north and west of both the climatological jet and the warm SST anomalies in the vicinity of Tehuantepec and Papagayo, but are centered directly over the Gulf of
Panama. The wind speed anomalies are modest in all three gap wind regions, generally less than $1 \mathrm{~m} \mathrm{~s}^{-1}$, and vary considerably from November to March and between ENSO events (not shown). The surface wind speed anomalies are stronger and appear to be more strongly tied to the underlying SSTs based on the NOAA high-resolution SST and wind data (Fig. S2 in the supplemental material), where the wind speed estimates are derived from a blend of in situ observations and measurements from several different satellites (Zhang et al. 2006).

\section{b. Processes that influence NETP SSTS}

\section{1) SURFACE FORCING}

Superimposed on a broad pattern of ENSO-related SST anomalies in the eastern tropical Pacific are anomalies of much larger amplitude in the gap wind regions. What causes the SSTs in TT, PP, and PN to depart from the broad response to ENSO in the NETP? Given that the gap winds drive the cold pools in the mean and that there are changes in the winds during ENSO events, suggests that they may influence SST anomalies, via winddependent processes including surface heat fluxes, Ekman heat transport, and Ekman pumping. ENSO-driven SSTs may also respond to ocean processes, such as Rossby and coastally trapped waves, vertical mixing, and eddies.

The climatological latent heat flux $\left(Q_{\mathrm{lh}}\right.$, shaded, positive into the ocean) and SST (contours) are shown in Fig. 5a. The latent heat flux cools (negative values) the NETP, where the large-scale pattern of $Q_{\mathrm{lh}}$ generally corresponding to regions of stronger winds (Fig. 4a) but shifted slightly north of the coldest SSTs, as the latter, via its control of the surface specific humidity, reduces the upward $Q_{\mathrm{lh}}$. The magnitude of $Q_{\mathrm{lh}}$ is especially large in the Gulf of Tehuantepec where it exceeds $200 \mathrm{~W} \mathrm{~m}^{-2}$ (Fig. 5a) and contributes to the SST minimum at TT, but is much smaller over the Costa Rica Dome and the Gulf of Panama.

The $Q_{\mathrm{lh}}$ anomalies (Fig. 5b) are negative over TT, PP, and $\mathrm{PN}$ regions with amplitudes reaching $50 \mathrm{~W} \mathrm{~m}^{-2}$ near the coast and extending over the positive SST in the Gulfs of Tehuantepec and Papagayo. Given that the turbulent heat fluxes depend on both the wind speed and air-sea temperature difference, positive SST anomalies as well as stronger winds enhance the ocean-atmosphere heat flux over the gap wind regions during El Niño. Thus, the latent heat fluxes damp, rather than generate, the ENSO-related SST anomalies. Solar radiation, the other large surface flux in the tropics, does not greatly influence the SST anomalies in the gap wind regions, although it does act to warm the ocean along the southern edge of the domain (see Fig. S3a in the supplemental material). The anomalous net surface heat 
Qlh (W m ${ }^{-2}$,shaded) SST $\left({ }^{\circ} \mathrm{C}\right.$,contour $)$
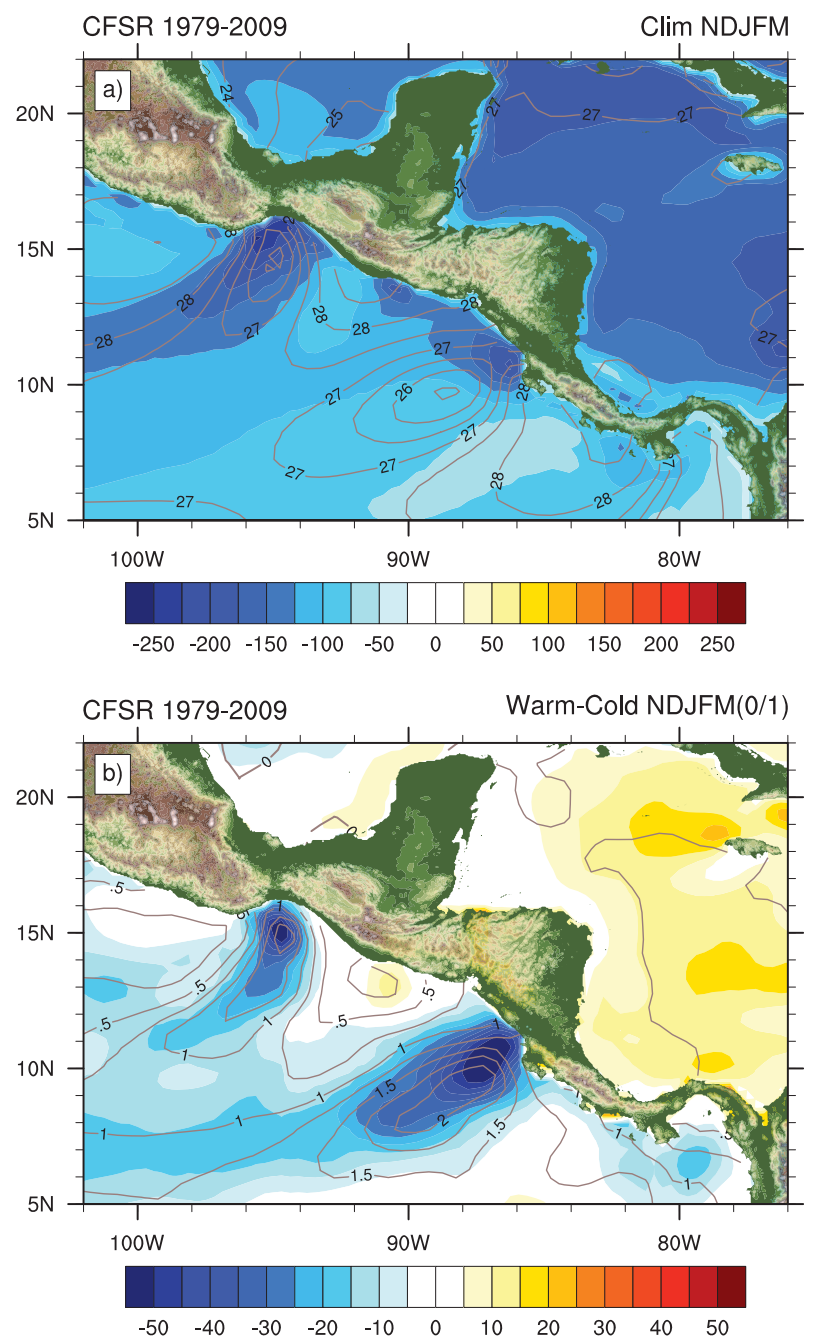

FIG. 5. (a) Mean and (b) El Niño-La Niña composite: SST (contours) and latent heat flux into the ocean (shading) during NDJFM. The contour (shading) intervals are $0.5^{\circ} \mathrm{C}\left(25 \mathrm{~W} \mathrm{~m}^{-2}\right)$ for (a) and $0.5^{\circ} \mathrm{C}\left(5 \mathrm{~W} \mathrm{~m}^{-2}\right)$ for (b). Data are from CFSR.

fluxes (see Fig. S3b in the supplemental material) are similar to the latent values as are the ENSO-related flux anomalies from the objectively analyzed air-sea fluxes project (OAFlux; Yu and Weller 2007; not shown).

The Ekman ocean heat transport $Q_{\text {ek }}$ is given in flux form by $-c / f(\mathbf{k} \times \boldsymbol{\tau}) \nabla \mathrm{SST}$, where $c$ is the specific heat of seawater, $f$ is the Coriolis parameter, $\mathbf{k}$ is the unit normal vector, and $\tau$ is the surface wind stress. The $Q_{\mathrm{ek}}$ exhibits positive-negative couplets of large amplitude ( $>100 \mathrm{~W}$ $\mathrm{m}^{-2}$ ) in the TT, PP, and PN regions (Fig. 6a). Since the mean northeasterly winds flow over cold SSTs, Ekman advection to the right of the wind in the Northern Hemisphere, results in cooling (warming) to the northwest (southeast) of the axis in minimum SSTs. As a result,
Qek (W m ${ }^{-2}$, shaded) SST $\left({ }^{\circ} \mathrm{C}\right.$,contour $)$
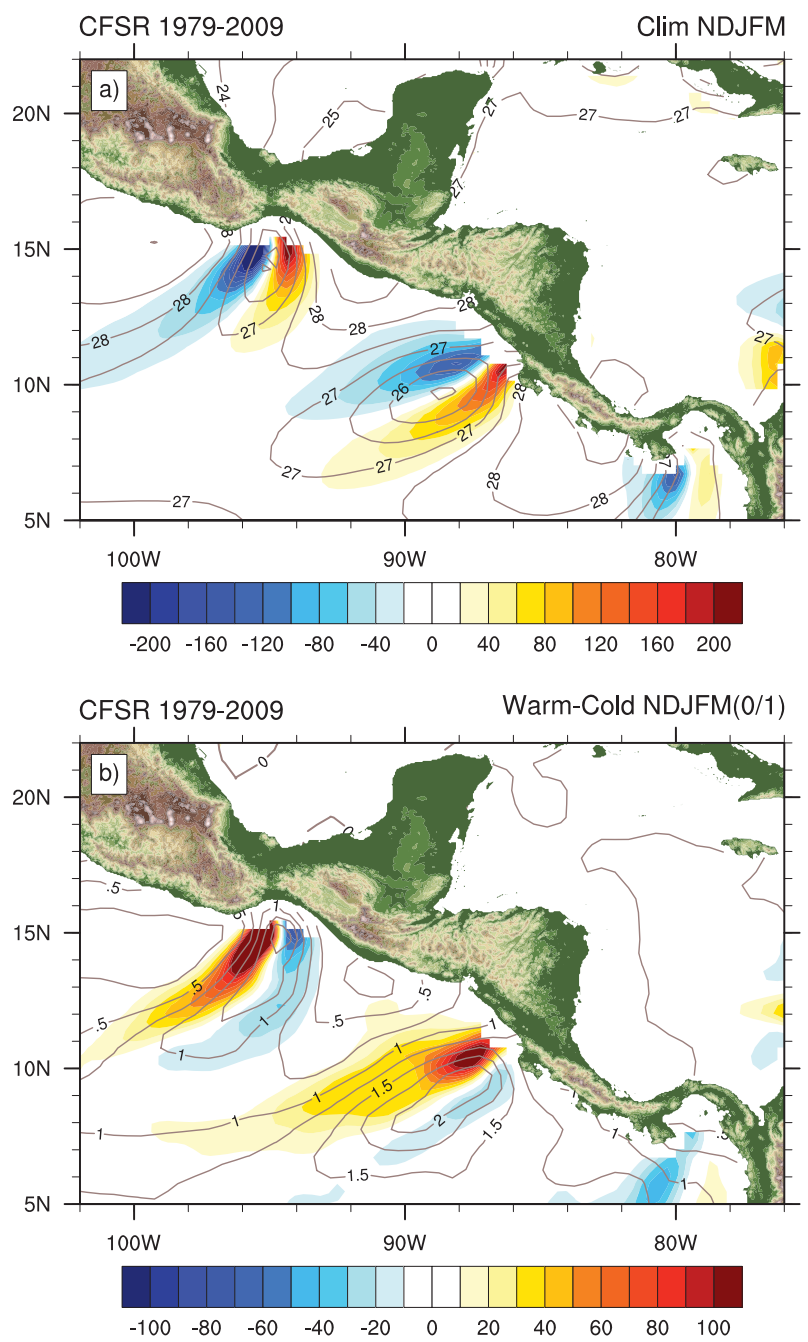

FIG. 6. (a) Mean and (b) El Niño-La Niña composite SST (contours) and Ekman heat transport (shaded) in flux form $(-c / f \mathbf{k} \times$ $\tau \nabla S S T$ ) during NDJFM. The contour (shading) intervals are $0.5^{\circ} \mathrm{C}$ $\left(20 \mathrm{~W} \mathrm{~m}^{-2}\right)$ for (a) and $0.25^{\circ} \mathrm{C}\left(10 \mathrm{~W} \mathrm{~m}^{-2}\right)$ for (b). Data are from CFSR.

$Q_{\text {ek }}$ is in quadrature with the SST centers and is of large amplitude because of the strong winds and SST gradients along the edges of the cold pools.

The $Q_{\mathrm{ek}}$ anomalies, like the climatological values, also have a dipole structure in all three regions, but at TT and PP the anomalous and climatological $Q_{\mathrm{ek}}$ values are collocated but out of phase, while in the PN region they are in phase (Fig. 6b). In the TT and PP regions the $Q_{\mathrm{ek}}$ anomalies are primarily due to the mean winds flowing over the anomalous SST gradient, the northwestward Ekman advection results in warming (cooling) to the northwest (southeast) of the ENSO SST anomaly. In the PN region, both the mean and anomalous $Q_{\mathrm{ek}}$ are 
$\nabla \times(\mathrm{TAU} / \rho f)\left(10^{-6} \mathrm{~m} \mathrm{~s}^{-1}\right.$, shaded $) \mathrm{SST}\left({ }^{\circ} \mathrm{C}\right.$, contour $)$

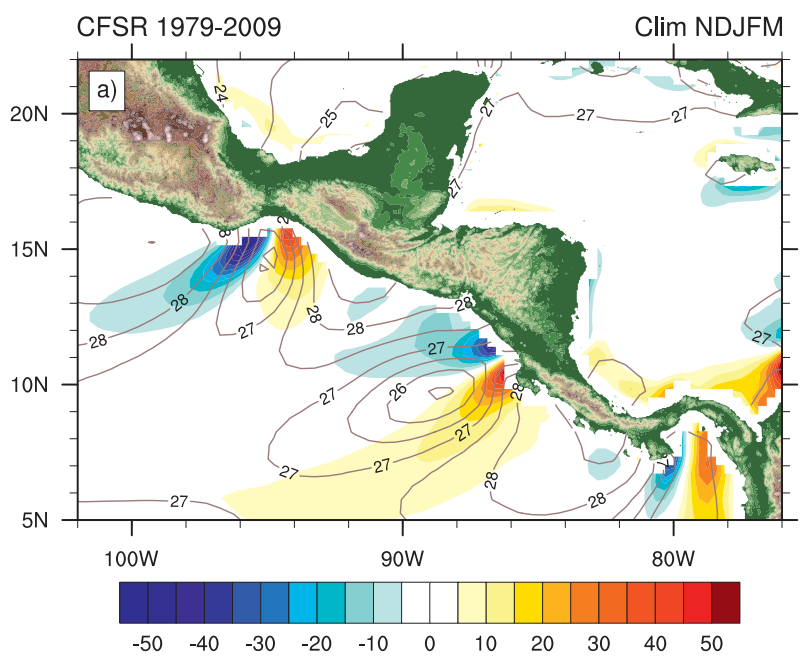

CFSR 1979-2009 Warm-Cold NDJFM(0/1)

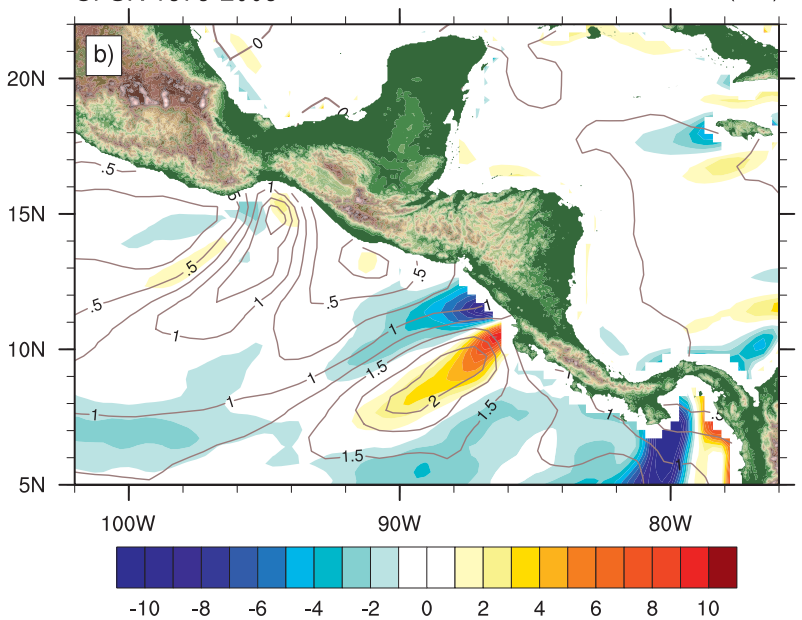

FIG. 7. (a) Mean and (b) El Niño-La Niña composite SST (contours) and Ekman pumping $\left[W_{\mathrm{ek}}=\nabla \times(\boldsymbol{\tau} / \rho f)\right]$ positive upward during NDJFM. The contour (shading) intervals are $0.5^{\circ} \mathrm{C}$ $\left(5 \times 10^{-6} \mathrm{~m} \mathrm{~s}^{-1}\right)$ in (a) and $0.25^{\circ} \mathrm{C}\left(1 \times 10^{-6} \mathrm{~m} \mathrm{~s}^{-1}\right)$ in (b). Data are from CFSR.

negative and of greatest amplitude to the west of $80^{\circ} \mathrm{W}$. Here the $Q_{\text {ek }}$ anomalies appear to be dominated by the anomalous wind (i.e., the anomalous Ekman currents advect the mean cold water in the center of the PN region to the northwest). The amplitude of the anomalous Ekman transport is fairly large, with values exceeding $30 \mathrm{~W} \mathrm{~m}^{-2}$ in all three regions and more than $80 \mathrm{~W} \mathrm{~m}^{-2}$ in portions of TT and PP. However, the $Q_{\mathrm{ek}}$ and SST anomalies are in quadrature at TT and PP, while at PN the $Q_{\text {ek }}$ anomalies are weaker and do not generally correspond to the structure of the SST anomalies, which suggests that the Ekman transport is not the primary driver of SST anomalies in the gap wind regions, but may influence their spatial distribution.

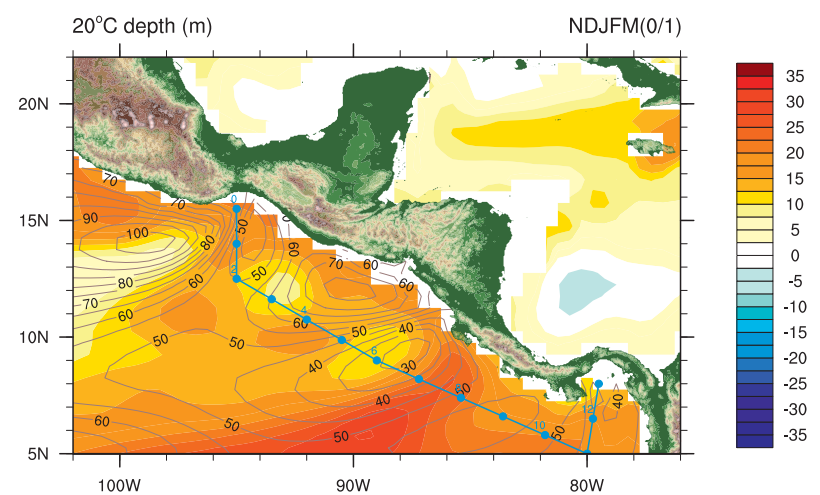

FIG. 8. Mean (contours) and El Niño-La Niña composite (shading) depth of the $20^{\circ} \mathrm{C}$ isotherm (Z20) during NDFJM. The contour (shading) interval is $5 \mathrm{~m}(2.5 \mathrm{~m})$. The blue line denotes the transect used in Fig. 9, with the dots numbered from 0 at the western end to 13 at the eastern end. The data are from CFSR.

The vertical velocity in the upper ocean, as well as the local and remote structure of the thermocline and SST, are influenced by Ekman pumping $W_{\mathrm{ek}}$, given by $\nabla \times$ $(\tau / \rho f)$, where $\rho$ is the seawater density. The mean northeasterly jets in the lee of the mountain gaps (Fig. 4a) create positive (negative) wind stress curl and thus upward (downward) motion via $W_{\text {ek }}$ on their southeast (northwest) flank (Fig. 7a). The $W_{\text {ek }}$ forcing associated with the gap wind jets excites westward-propagating Rossby waves that influence the thermocline structure resulting in thermocline domes and the corresponding cold SST pools located below and to the west of the mean upward Ekman motion (Xie et al. 2005; Kessler 2006). Similar results are found in the CFSR reanalysis: the mean thermocline, as indicated by the depth of the $20^{\circ} \mathrm{C}$ isotherm [Z20, contours in Fig. 8 and in Fig. S4b (in the supplemental material)], is substantially shallower in the three gap wind regions relative to the rest of the NETP. Indeed, Z20 is only $30 \mathrm{~m}$ deep in the Costa Rica Dome and within $40 \mathrm{~m}$ of the surface in the Gulfs of Tehuantepec and Panama.

The $W_{\text {ek }}$ anomalies, shown in Fig. 7b, are generally collocated with the climatological values with maximum amplitude near the coast, although they transition to a weak meridional dipole in the vicinity of TT $\left(12^{\circ}\right.$ $15^{\circ} \mathrm{N}$, west of $96^{\circ} \mathrm{W}$ ) where the climatological $W_{\mathrm{ek}}$ values are negative. Given that the mean and anomalous Ekman pumping are in phase one would expect negative SST anomalies and a shallower thermocline, but the reverse occurs in all three gap wind regions. For example in PP, upward (positive) $W_{\mathrm{ek}}$ anomalies, which would tend to shoal the thermocline, are located over and to the east of anomalously warm SSTs (Fig. 7b) and a deeper thermocline (Fig. 8). In addition, the $W_{\mathrm{ek}}$ anomalies in TT appear to be too small to appreciably 
influence the thermocline. Thus, Ekman pumping and the other surface flux terms discussed above are not the primary drivers of the ENSO-related SST and thermocline anomalies, and other oceanic processes likely play important roles in creating these anomalies.

\section{2) OCEAN PROCESSES}

During ENSO events, Kelvin waves propagate eastward along the equator and then poleward upon reaching the coast of the Americas. Some of the Kelvin wave energy can be refracted as westward-propagating Rossby waves, whose energy is primarily confined to the eastern Pacific (Kessler and McPhaden 1995; Fu and Qiu 2002). While a detailed analysis of the wave dynamics in the NETP is beyond the scope of this paper, evidence for wave propagation is presented via a Hovmöller diagram of Z20 depth for a path with three segments: the first extends eastward along the equator in the eastern Pacific, the second continues north along the Central American coast to $9^{\circ} \mathrm{N}$, and the third extends west at $9^{\circ} \mathrm{N}$. The transect values for composite El Niño and La Niña conditions obtained from CFSR data are shown in Fig. 9; a similar analysis based on the control ROMS simulation (described in section 3c) is presented in Fig. S5 (in the supplemental material). The thermocline is anomalously deep during El Niño and shallow during La Niña events over all three segments with relatively rapid propagation of Kelvin waves on the equator that continue northwestward as Kelvin (and other coastally trapped waves) along the Central American coast and are finally refracted as slower westward Rossby waves at $9^{\circ} \mathrm{N}$. The off-equatorial westward propagation of Z20 anomalies occurs throughout the NETP where the propagation speed decreases with latitude (not shown), consistent with Rossby wave theory. However, the full evolution of the upper ocean in the NETP during ENSO is complex and includes a number of factors that impact the coastal waves and Rossby wave characteristics (e.g., Kessler and McCreary 1993; Kessler and McPhaden 1995; Strub and James 2002) as well as the formation and westward propagation of eddies (Zamudio et al. 2006). For example, the poleward propagation appears to be influenced by the irregular coastline north of $\sim 6^{\circ} \mathrm{N}$ and there may be two source regions for the westward-propagating anomalies at $9^{\circ} \mathrm{N}$ : one adjacent to the coast and the second approximately $3^{\circ}-5^{\circ}$ offshore.

As a result of the ENSO-generated waves, the thermocline anomalies have a wedge shape in the NETP: the thermocline deepens through the NETP with larger anomalies along the coast that broaden toward the equator as found by Kessler (2006) and in CFSR and SODA, as depicted in Figs. 8 and S4b (in the supplemental material), respectively. An additional prominent feature is the enhanced deepening of the thermocline anomalies along the southern flank of the Costa Rica Dome that extends farther southwestward into the Pacific Ocean. Changes in the ocean currents in the NETP are primarily confined to the upper $100 \mathrm{~m}$ and consistent with geostrophy (as indicated by the gradient of Z20) contain anomalous cyclonic flow around the Costa Rica Dome, enhancing the mean circulation, and anomalous anticyclonic flow centered at $13.5^{\circ} \mathrm{N}, 95^{\circ} \mathrm{W}$ tending to oppose the mean circulation near TT and shift it slightly to the south (see Fig. S6 in the supplemental material).

Several aspects of the mean upper-ocean temperature structure and how it varies during ENSO events can impact the SST anomalies in the NETP. The climatological vertical temperature structure (contours) including the depth of the mean $20^{\circ} \mathrm{C}$ isotherm (black line) and mixed layer depth (MLD; thin dashed line) as well as the Z20 depth during El Niño (red line) and La Niña events (blue line) are shown in Fig. 10a for a transect through the CFSR output (blue line in Fig. 8) extending from TT (points 0-2) south through PP (points 6-7) and terminating at PN (points 10-13). Temperature anomalies and the MLD during El Niño and La Niña along this transect are shown for CFSR in Fig. 10b. For a more comprehensive view of the ENSO signal in the NETP we show the following: (i) the temperature departures from climatology for the 1997/98 El Niño and 1988/89 La Niña events in CFSR (Fig. S7 in the supplemental material), (ii) the composite anomalies from SODA along this transect (Fig. S4c in the supplemental material), and (iii) the mean and anomalous SODA temperatures for more traditional cross sections at $14^{\circ}, 9^{\circ}$, and $6.5^{\circ} \mathrm{N}$ (Fig. S8 in the supplemental material).

The thermocline is substantially deeper along the entire transect during El Niño than it is during La Niña events (Fig. 10a); as a result large positive anomalies $\left(>3^{\circ} \mathrm{C}\right)$ occur in the thermocline and decrease toward the surface. The ENSO-driven thermocline changes can influence SSTs via vertical mixing processes including entrainment and the depth of the mixed layer. The MLD is generally shallower than $40 \mathrm{~m}$ throughout the NETP and less than $25 \mathrm{~m}$ in most of the gap wind regions (see Fig. 10 and Fig. S9 in the supplemental material), while the thermocline is located below $50 \mathrm{~m}$ at TT and PN during El Niño events. Thus, the relatively cold water in the thermocline is less likely to be entrained into the surface mixed layer during El Niño and more likely during La Niña. In addition, The MLD is 5-10 m deeper during El Niño than La Niña, which may also enhance the entrainment of anomalously warm water at depth into the surface layer. The mixed layer during El Niño is slightly shallower relative to the thermocline and large temperature anomalies at depth in PN (point 12) when 
(a)

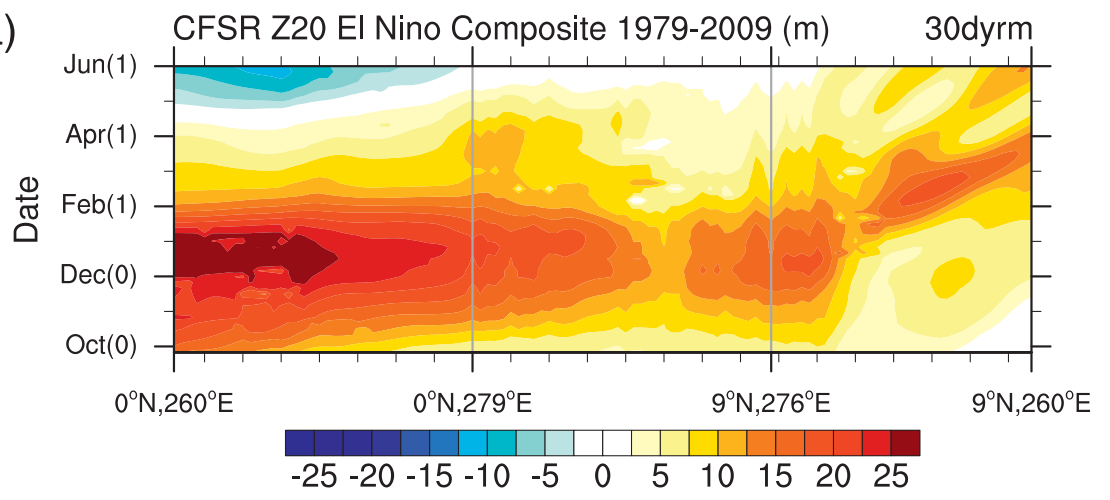

(b)

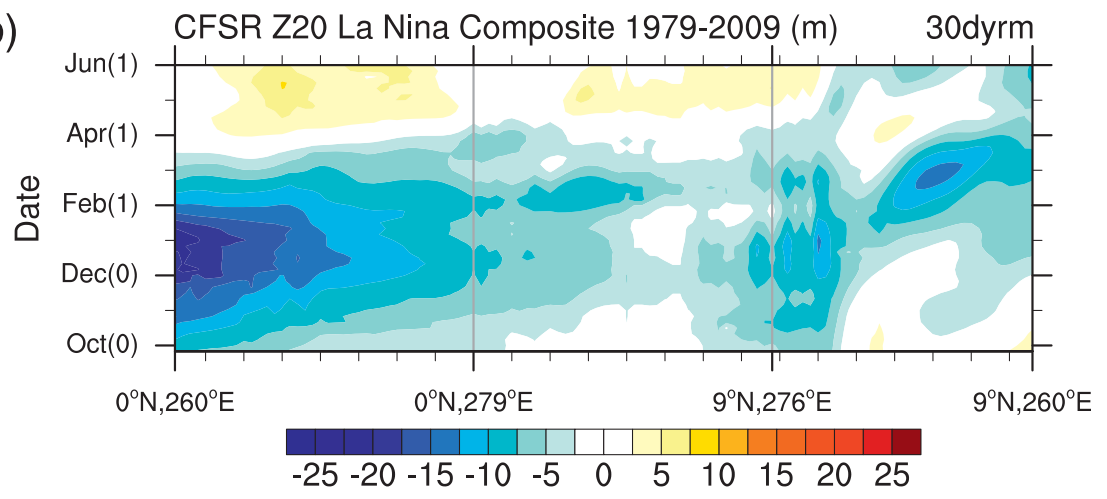

(c)

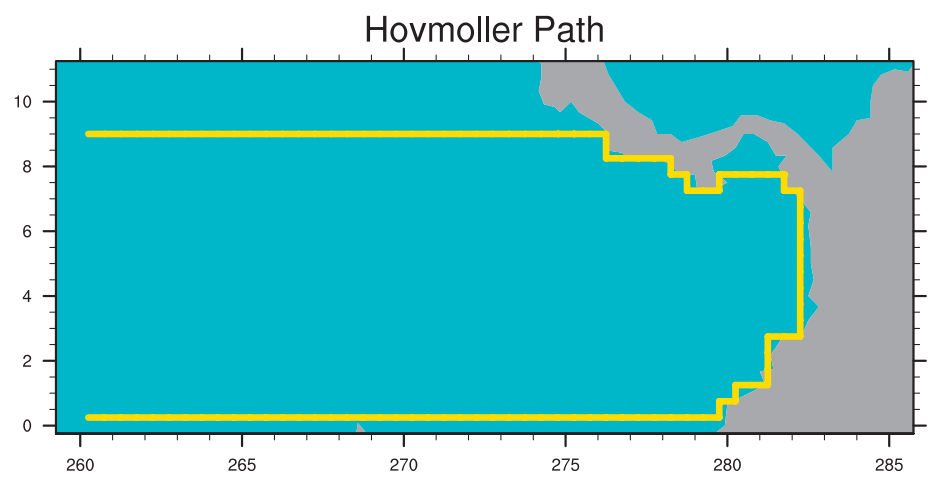

FIG. 9. Hovmöller (time-distance) diagram of the composite Z20 depth (m) for (a) El Niño events and (b) La Niña events for the path shown in (c). The path has three segments separated by vertical lines, including: (i) east from $100^{\circ} \mathrm{W}\left(260^{\circ} \mathrm{E}\right)$ to the South American coast along the equator; (ii) northwestward from $0^{\circ}$ to $9^{\circ} \mathrm{N}$ along the South American coast, and (iii) west from the coast to $100^{\circ} \mathrm{W}$ along $9^{\circ} \mathrm{N}$. The time coordinate spans 8 months from $\operatorname{Oct}(0)$ to Jun(1) based on the 30-day running mean of pentad averages obtained from CFSR. The values along $0^{\circ}$ and $9^{\circ} \mathrm{N}$ are the average of three points along and to the north of the transect, while the values in the second segment are from single points adjacent to the coast.

compared with PP and TT, which may partly explain why the anomalies at depth have a more limited impact on SSTs in PN.

In addition to the region-wide mean increase in thermocline depth, local changes in the Z20 displacement can also impact the temperature anomalies: the maximum anomalies $\left(>4.5^{\circ} \mathrm{C}\right)$ generally occur where the Niño-Niña
Z20 change is largest: at TT (point 1), the southern portion of PP (between points 7 and 8), and west of PN (point 10), see Figs. 8 and 10 (and Fig. S4 in the supplemental material). In the vicinity of PP, the largest SST anomalies occur between the climatological minimum in SST and Z20 (between points 5 and 6) and the large temperature-Z20 anomalies at depth (between 

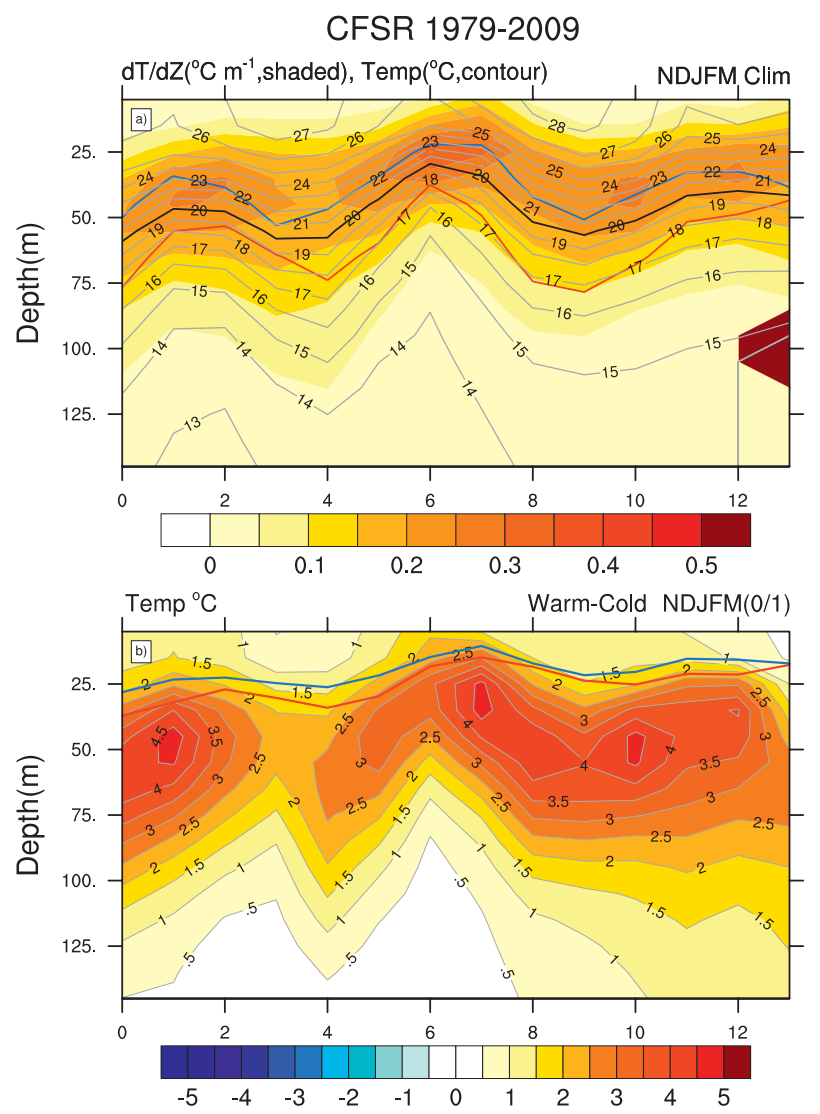

FIG. 10. Cross section along the transect shown in Fig. 8 beginning in the Gulf of Tehuantepec (0), passing through the Costa Rica Dome (6) and ending at the Gulf of Panama (13) of (a) the mean temperature (contours, $1^{\circ} \mathrm{C}$ interval) and mean vertical temperature gradient (shading, $0.05^{\circ} \mathrm{C} \mathrm{m}^{-1}$ ). Also shown are the mean MLD (black dashed line), and the $20^{\circ} \mathrm{C}$ isotherm depth (Z20) for the mean (black line), El Niño (red line), and La Niña (blue line) composites. (b) El NiñoLa Niña composite temperature (contours and shading, interval $0.5^{\circ} \mathrm{C}$ ) and the mixed layer depth for the El Niño composite (red line) and La Niña composite (blue line). The data are from CFSR.

points 7 and 8 ), suggesting that both a uniform change in depth of the mean temperature structure and localized changes in the thermocline depth influence the SST anomaly pattern.

The SST anomalies may also be influenced by horizontal variations in the vertical temperatures structure. While the vertical temperature gradient (shading in Fig. 10a) in the thermocline is fairly uniform in the NETP, there are local maxima that are most pronounced between approximately 25 and $50 \mathrm{~m}$ at TT (points 1-2), PP (points 5-7), and PN (points 10-12), which create larger temperature anomalies when the thermocline is displaced in these areas. Thus, several processes, including both the region-wide and local deepening of the thermocline, the depth of these changes relative to the surface mixed layer, and the vertical temperature within the thermocline may all contribute to the location of the maximum SST anomaly in the NETP region.

\section{c. Model simulations}

We further examine the roles of surface forcing and ocean processes in generating ENSO-related SST and Z20 anomalies using a set of ROMS (described in section 2b) simulations. The control (CTL) integration includes timevarying lateral boundary and surface heat, momentum, and freshwater fluxes obtained from CFSR over the period 1979-2008. In the V-SFC experiment, we retain the fully variable surface forcing fields over the 30 -yr simulation, but the lateral ocean boundary conditions from the control are replaced with the monthly climatology. Similarly, the V-OBC experiment uses variable ocean boundary conditions but climatological surface forcing. Hence, V-SFC depicts the impact of ENSO on the NETP via the atmosphere, while $\mathrm{V}-\mathrm{OBC}$ retains the influence of ENSO on the NETP via the ocean, primarily through waves that propagate poleward along the coast from the equator.

The climatological mean (contours) and anomalies (shading) of SST and Z20 from the CTL simulation are shown in Figs. 11a,b. The climatological SSTs are at minima in the three gap regions, where the mean thermocline is shallower than the surrounding ocean. The SST-Z20 anomalies show a broad warming and deepening of the thermocline in the NETP associated with ENSO. Within this region-wide anomaly pattern, the SST anomalies are enhanced, reaching $\sim 3^{\circ} \mathrm{C}$ in TT and within and to the south of PP. The anomalous deepening of Z20 is more pronounced $(>30 \mathrm{~m})$ from the coast at $\sim 10^{\circ} \mathrm{N}$ to the southwest passing south of the Costa Rica thermocline dome. Both the mean and anomalous SST and Z20 fields from ROMS are in broad agreement with CFSR (Figs. 2a and 8) and SODA (Fig. S4 in the supplemental material). The anomalies in the gap wind regions are generally reproduced although they are somewhat larger than in the reanalyses and there are some differences in the detailed structure of both the SST and $\mathrm{Z} 20$ fields. Considering that there is no damping on the models response to the surface forcing, both the mean and anomalous SST field are simulated reasonably well.

In V-SFC, without interannual variations in lateral ocean heat transport at the model's boundaries, localized SST warming, and thermocline deepening of the major gap wind regions are absent and negative SST anomalies occur in the PP region (Figs. 11c,d). The model results confirm that the surface forcing is not the primary driver for the ENSO-induced SST and thermocline anomalies.

In $\mathrm{V}-\mathrm{OBC}$, with interannual variability at the ocean boundaries, pronounced surface warming occurs in all three gap wind regions including PN (Fig. 11e). The SST 

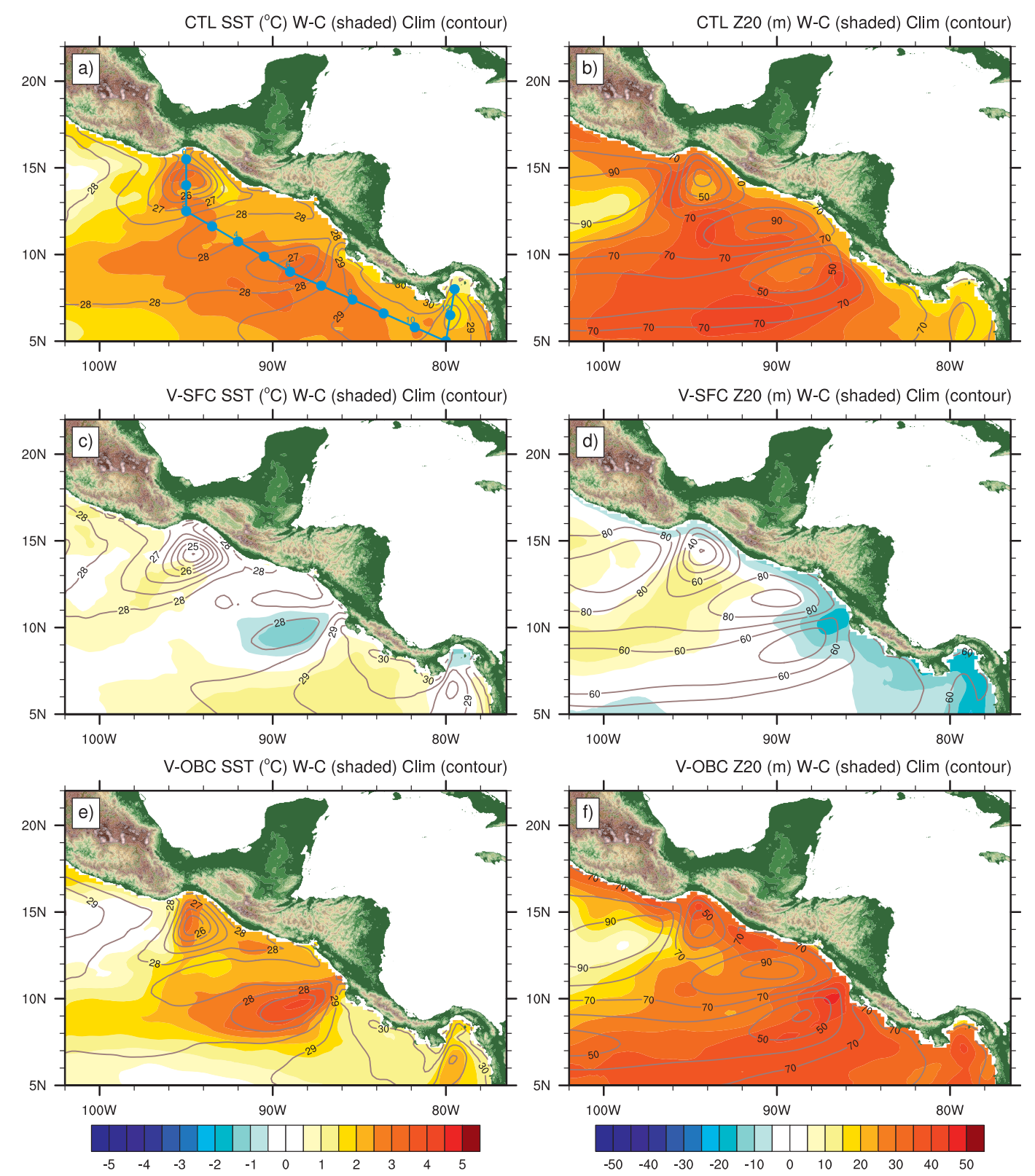

FIG. 11. The mean (contours) and El Niño-La Niña composite (shading) (left) SST and (right) Z20 for the three ROMS simulations: (a),(b) the control (CTL) with interannually varying surface and boundary forcing; (c),(d) the VSFC simulation with varying surface forcing but repeating climatological boundary forcing; and (e),(f) V-OBC simulation with varying ocean boundary forcing, but repeating climatological surface forcing. All of the simulations are conducted over the period 1979-2008, where the surface forcing fields are from CFSR and the boundary values are obtained from SODA. The contour (shading) intervals are $0.5^{\circ} \mathrm{C}\left(0.3^{\circ} \mathrm{C}\right)$ for the left panels and $5 \mathrm{~m}(4 \mathrm{~m})$ for the right panels.

anomalies are somewhat larger in TT, $\mathrm{PP}$, and $\mathrm{PN}$ in the $\mathrm{V}-\mathrm{OBC}$ simulation compared with the CTL as the ENSO-induced evaporative cooling effect is not included in the former. The SST anomaly is large in PP $\left(>4^{\circ} \mathrm{C}\right)$ and centered over the Costa Rica Dome. The thermocline is deeper through the NETP and exhibits a localized deepening of more than $30 \mathrm{~m}$ to the south and east of the thermocline dome (Fig. 11f), resembling Z20 in the CTL and reanalyses. In vertical cross sections of the temperature anomalies along the transect depicted in Fig. 11a, the CTL and V-OBC, but not the V-SFC simulation, produce large subsurface positive 


\section{Warm-Cold Temp ${ }^{\circ} \mathrm{C}$}

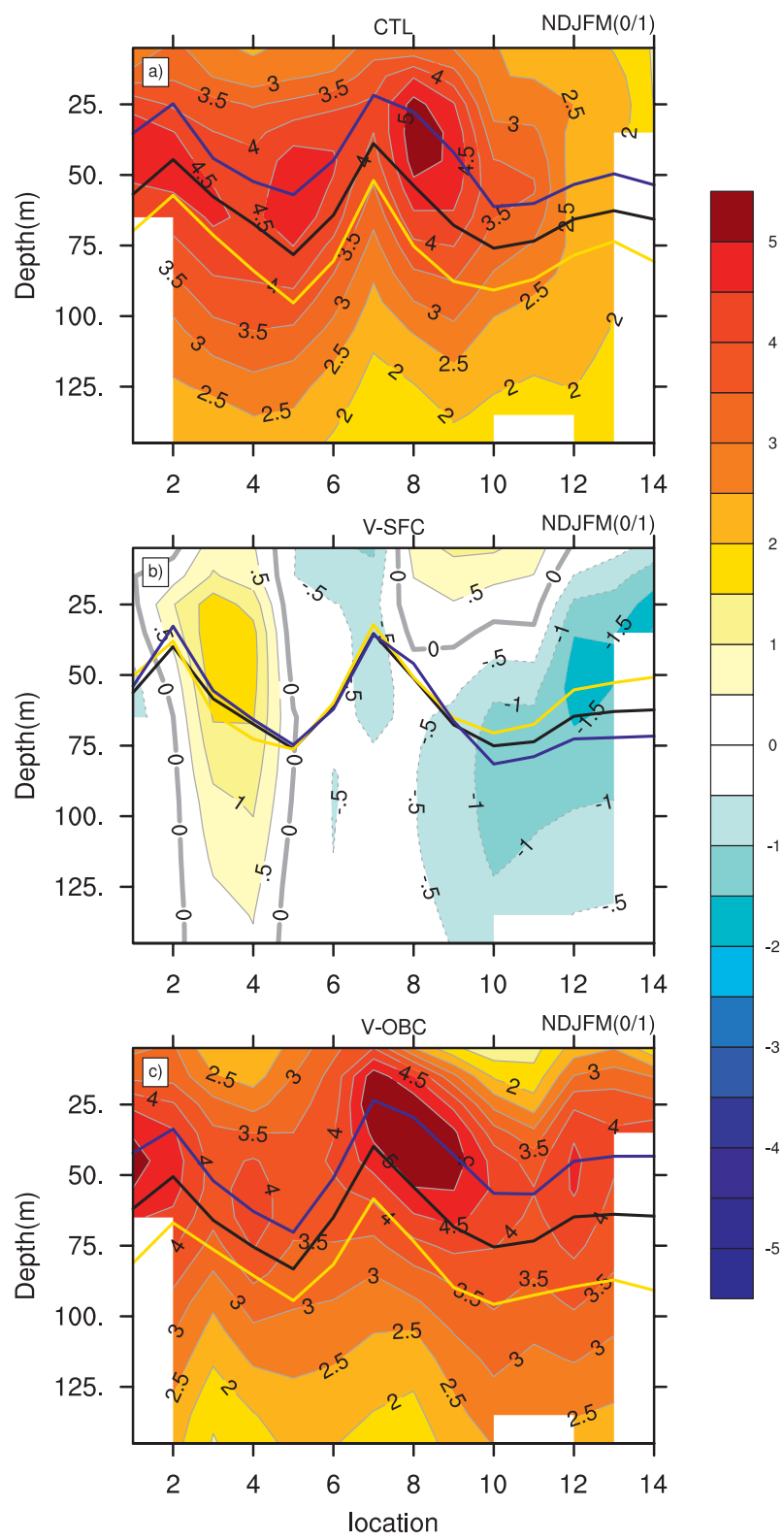

FIG. 12. Cross section along the transect shown in Fig. 11a of the composite El Niño-La Niña ocean temperature (contour-shading $0.5^{\circ} \mathrm{C}$ interval). Also shown are the $\mathrm{Z} 20$ depth for the mean (black line), and El Niño (yellow line) and La Niña (blue line) composites in the (a) CTL, (b) V-SFC, and (c) V-OBC simulations.

temperature anomalies, especially at 25-75-m depth in the TP and PP regions (Fig. 12), which resemble observations.

While the general SST and Z20 features are similar in the CTL and V-OBC simulations, there are differences in the detailed structure of the anomalies. A major difference between the CTL and V-OBC integrations occurs in the PN region (between points 11 and 14), where the anomalies are much larger throughout the upper ocean in the latter. In addition to the surface flux damping, the anomalous wind forcing (as isolated in the V_SFC experiment) appears to shoal the thermocline (Fig. 11d) and cause colder temperatures throughout the upper ocean in PN (Fig. 12b), which would be included in the CTL, but not the V-OBC experiment.

We perform an ocean mixed layer heat budget to evaluate the oceanic processes responsible for the SST anomalies in the three gap wind regions. The vertical temperature advection and vertical diffusion are inferred as the residual $R$ in a simplified heat budget equation:

$$
R=\rho c_{p} \operatorname{MLD}\left(\mathrm{SST}_{t}+H_{\mathrm{adv}}\right)-Q,
$$

where $\mathrm{SST}_{t}$ is the mixed layer temperature tendency, $H_{\text {adv }}$ is the net horizontal advection, and $Q$ is the net surface heat flux (positive into the ocean). Each term is computed offline based on monthly mean model outputs from 1979 to 2008, after which the November-March [NDJFM(0/1)] ENSO composite anomaly (El Niño-La Niña) fields are constructed. The ENSO anomalies for the budget terms in the CTL simulation averaged over the three gap wind regions are shown in Fig. 13. In all three regions, $R$, which includes vertical mixing and advection, contributes to the positive SST anomalies and is clearly the dominant term in PP. In contrast $Q$ is generally negative acting to impede the warming. The cooling is most pronounced at TT and PP because of higher latent and sensible heat loss during El Niño years associated with large $\Delta q$ and $\Delta T$ values. The $H_{\text {adv }}$ varies with region; it has a significant contribution to the warming from $\operatorname{Nov}(0)$ through $\operatorname{Jan}(1)$ in TT, is moderately strong in $\operatorname{Dec}(0)$ in PP, and is relatively small throughout the ENSO cycle in PN. The temperature tendency is relatively small in all three regions as there is compensation between the budget terms that control it. Although the budget component values may differ between the ROMS experiments and CFSR, the former suggests that the more rapid El Niño-induced warming in the fall at Tehuantepec in CFSR (Fig. 2), may be due to a combination of vertical processes and temperature advection while the strong warming at Papagayo in midto late winter primarily results from vertical processes.

\section{Summary and discussion}

In addition to the strong mean response of the ocean to gap winds near the Gulfs of Tehuantepec, Papagayo, and Panama, the results presented here demonstrate that ENSO also has a substantial impact on interannual 


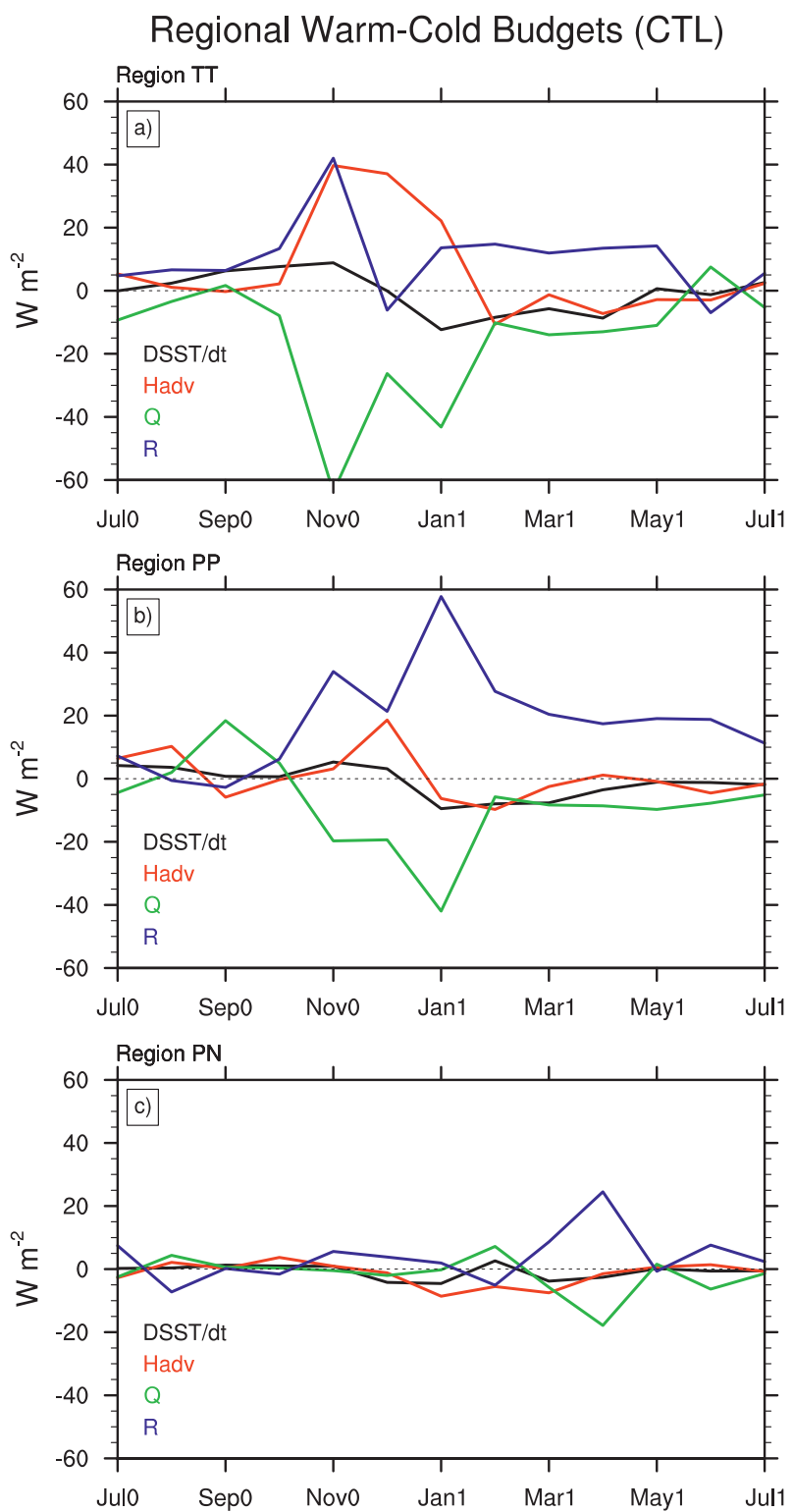

FIG. 13. Evolution of the El Niño-La Niña composite mixed layer temperature budget terms from the CTL simulation from July(0) to July(1) in the (a) TT, (b) PP, and (c) PN regions. The budget components are the mixed layer temperature tendency (black), horizontal advection $\left(H_{\mathrm{adv}}\right.$, red $)$, net surface heat flux $(Q$, green), and the residual ( $R$, blue). The first two terms have been multiplied by $\rho c_{p}$ MLD so all variables are in watts per meter squared.

variability of the ocean in these regions. During boreal winter when ENSO peaks, the normally cool SSTs are substantially warmer relative to the rest of the NETP in El Niño and colder during La Niña events, particularly in the PP region. Analyses of the atmospheric processes that could cause the ENSO-related anomalies indicates that the anomalous Ekman heat transport, while of large amplitude $\left(>50 \mathrm{~W} \mathrm{~m}^{-2}\right)$, is generally in quadrature with the SST anomalies, and the surface fluxes damp the anomalous SSTs. The damping results from increased evaporation above warm SST anomalies, due to an increase in the saturation vapor pressure as regulated by the Clausius-Clapeyron relationship, and by a modest increase in the surface wind speed in the gap wind regions. The positive SST anomalies may contribute to the higher surface wind speeds by altering the horizontal pressure gradient and by decreasing the static stability and thus mixing higher momentum air down to the surface (e.g., see Xie 2004; Chelton and Xie 2010; Small et al. 2008), but the extent to which the SST anomalies feedback on the atmospheric circulation is unclear and requires further study.

The mean jets flowing through the three gaps in the Central American mountains regulate the mean ocean structure. As shown by Xie et al. (2005) and Kessler (2006), Ekman pumping in conjunction with westwardpropagating Rossby waves raises the thermocline and brings cold water close to the surface west of the surface forcing. Similar mean Ekman-driven vertical motion and thermocline structure were found here using the longer CFSR dataset. In contrast, the ENSO-driven thermocline changes do not appear to be directly driven by the Ekman pumping, which is in phase with the climatological wind stress curl and thus would enhance upwelling, resulting in a shallower thermocline in the gap wind regions.

The temperature anomalies in the gap wind regions in CFSR and SODA appear to be due to large-scale ocean dynamics that result in a deeper thermocline over the entire NETP during El Niños and a shallower thermocline during La Niñas. As a result, the cold water within the thermocline is less likely to be vertically mixed to the surface during El Niño, especially in the gap wind regions where the thermocline is normally very close to the surface. The enhanced deepening of the thermocline south of the Costa Rica Dome likely contributed to the large positive SST anomalies within the Papagayo region. These findings were supported by regional ocean model experiments. A control simulation, with variable boundary forcing and surface fluxes, as well as the simulation with variable ocean boundary conditions but climatological surface fluxes reproduced the observed fields with anomalous warming over nearly all of the domain and enhanced warming in the Tehuantepec and Papagayo regions. However, the simulation with variable surface forcing but climatological ocean boundary conditions had little to no warming in the Tehuantepec and Panama regions and cooling in Papagayo with a shallower thermocline along the coast of Central America during El Niño. 


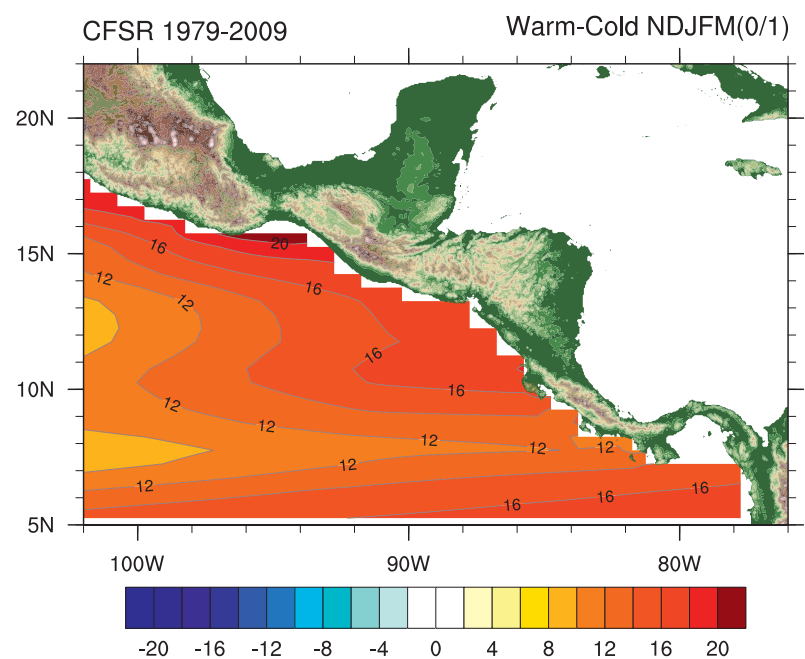

FIG. 14. El Niño-La Niña composite Z20 values as simulated by a linear Rossby wave model forced by the variability in Z20 at the eastern boundary. The contour-shading interval is $4 \mathrm{~m}$.

The thermocline changes are likely associated with ocean wave dynamics that include downwelling (upwelling) Kelvin waves that first move eastward along the equator and then poleward along the coast of the Americas during El Niño (La Niña) events. These waves are also included as perturbations along the western boundary near the equator in the CTL and V-OBC simulations. Kelvin and other boundary waves are confined close to the coast as the Rossby radius of deformation (where the amplitude of the waves decay by a factor of $\mathrm{e}^{-1}$ ) for the first baroclinic mode is approximately $150 \mathrm{~km}$ at $5^{\circ} \mathrm{N}$ and $50 \mathrm{~km}$ at $20^{\circ} \mathrm{N}$ in the eastern Pacific (e.g., Chelton et al. 1998). Much of the wave energy on interannual time scales, can propagate offshore via baroclinic Rossby waves, although their influence on the Pacific is mainly confined to within a few thousand kilometers of the coast (Kessler 1990). Indeed, Fu and Qiu (2002) found that much of the variability in sea surface height in the NETP can be attributed to boundary-forced Rossby waves.

The general features of the mean thermocline in the NETP were simulated using a first mode linear Rossby model driven by wind and boundary forcing (Kessler 2006), while several studies including Fu and Qiu (2002) and Capotondi and Alexander (2001) have used this simple model to examine sea surface height or thermocline depth anomalies in the subtropical North Pacific. Here we examine the ENSO-driven thermocline structure using a linear first-mode Rossby wave model in which the eastern boundary values are given by the depth of the $20^{\circ} \mathrm{C}$ isotherm in CFSR along the Central American coast over the period 1979-2008. Given the results from Fu and Qiu (2002) and our finding that the wind stress curl would tend to decrease rather than increase the thermocline depth during El Niño events in the gap wind areas, we neglect the wind forcing. The Z20 depths for the composite of El Niño minus La Niña events from the Rossby wave model are shown in Fig. 14. The model obtains the broad structure of the Z20 anomalies seen in the CFSR and SODA reanalyses (Fig. 8 and S4b in the supplemental material) and ROMS (Fig. 11b), with a deeper thermocline over the domain during ENSO events that extends farthest offshore along the southern end of the domain, where the Rossby waves propagate fastest, and somewhat larger amplitude signals at $\sim 11^{\circ} \mathrm{N}$ and in the Gulf of Tehuantepec. The model lacks the detailed structures seen in observations, but its greatest deficiency is the absence of the large positive Z20 anomalies extending southwest from the coast at $\sim 10^{\circ} \mathrm{N}$ and along the southern flank of the Costa Rica Dome. Differences with observations may be due to the simplicity of the Rossby wave model, which in addition to omitting the local wind forcing, neglects a wide array of processes including changes in refraction with a variable coastline, wave dispersion, vertical propagation, higher-order modes, advection by currents, and variations in the mean potential vorticity, which can all impact the Rossby wave characteristics in the NETP (e.g., see Schopf et al. 1981; Kessler 1990; Kessler and McCreary 1993; Kessler and McPhaden 1995; Killworth et al. 1997).

While the explanation for the detailed structure of the oceans' response to ENSO in the NETP is not resolved, especially the large thermocline anomalies in the vicinity of Papagayo, it may well involve ocean eddies, which are prominent west of Central America (see review by Willett et al. 2006). Palacios and Bograd (2005) found considerable interannual variability in eddy activity, with more eddies of greater intensity and longevity during El Niño relative to La Niña years over the period 1992-2004. They suggested that changes in eddy activity were likely generated by more strong wintertime cold surges into Central America during El Niño, but also noted that changes in the background sea level and the passage of strong coastally trapped Kelvin waves associated with ENSO could also modulate eddy activity. Zamudio et al. (2001) found that during strong El Niño events, a narrow current associated with a downwelling Kelvin wave develops, which becomes unstable and breaks forming anticyclonic eddies that propagate away from the coast at $\sim 18^{\circ} \mathrm{N}$. Anticyclonic eddies, with a deeper thermocline, were also more prevalent and stronger in the vicinity of Tehuantepec during the 1997 El Niño than during the 1998 and 1999 La Niña events, where the modulation in eddy generation was again linked to coastally trapped waves that were generated in the equatorial Pacific (Zamudio et al. 2006). The role of 
eddy generation/maintenance in the NETP response to ENSO may also be influenced by barotropic and/or baroclinic instability and warrants further study.

Acknowledgments. This research was supported by grants from the NOAA office of Global Programs and the NSF Climate and Global Dynamics Division. We thank Justin Small for his insightful comments on atmosphere and ocean processes in the gap wind regions, and Bo Qiu, Weiqing Han, and Baylor Fox-Kemper for their insights on Rossby wave propagation in the NETP. We also acknowledge the support from the NASA Ocean Vector Wind Science Team.

\section{REFERENCES}

Capotondi, A., and M. A. Alexander, 2001: Rossby waves in the tropical North Pacific and their role in decadal thermocline variability. J. Phys. Oceanogr., 31, 3496-3515.

Carton, J. A., and B. S. Giese, 2008: A reanalysis of ocean climate using Simple Ocean Data Assimilation (SODA). Mon. Wea. Rev., 136, 2999-3017.

—, G. A. Chepurin, X. Cao, and B. S. Giese, 2000: A Simple Ocean Data Assimilation analysis of the global upper ocean 1950-95. Part I: Methodology. J. Phys. Oceanogr., 30, 294-309.

Chelton, D. B., and R. E. Davis, 1982: Monthly mean sea level variability along the west coast of North America. J. Phys. Oceanogr., 12, 757-784.

— at oceanic mesoscales. Oceanography, 23, 52-69.

- R. A. de Szoeke, M. G. Schlax, K. E. Naggar, and N. Siwertz, 1998: Geographical variability of the first baroclinic Rossby radius of deformation. J. Phys. Oceanogr., 28, 433-460.

, M. H. Freilich, and S. K. Esbensen, 2000: Satellite observations of the wind jets off the Pacific coast of Central America. Part I: Case studies and statistical characteristics. Mon. Wea. Rev., 128, 1993-2018.

Clarke, A. J., 1988: Inertial wind path and sea surface temperature patterns near the Gulf of Tehuantepec and Gulf of Papagayo. J. Geophys. Res., 93, 15 491-15 501.

— levels. J. Phys. Oceanogr., 24, 661-680.

Enfield, D. B., and J. S. Allen, 1980: On the structure and dynamics of monthly mean sea level anomalies along the Pacific coast of North and South America. J. Phys. Oceanogr., 10, 557-588.

Fairall, C. W., E. F. Bradley, D. P. Rogers, J. B. Edson, and G. S. Young, 1996: Bulk parameterization of air-sea fluxes for Tropical Ocean Global Atmosphere Coupled Ocean-Atmosphere Response Experiment. J. Geophys. Res., 101, 3747-3764.

Fiedler, P. C., 2002: The annual cycle and biological effects of the Costa Rica Dome. Deep-Sea Res. I, 49, 321-338.

Fu, L.-L., and B. Qiu, 2002: Low-frequency variability of the North Pacific Ocean: The roles of boundary- and wind-driven baroclinic Rossby waves. J. Geophys. Res., 107, 3220, doi:10.1029/ 2001JC001131.

Furue, R., J. P. McCreary Jr., and Z. Yu, 2009: Dynamics of the Northern Tsuchiya Jet. J. Phys. Oceanogr., 39, 2024-2051.

Haidvogel, D. B., H. G. Arango, K. Hedstrom, A. Beckmann, P. Malanotte-Rizzoli, and A. F. Shchepetkin, 2000: Model evaluation experiments in the North Atlantic basin: Simulations in nonlinear terrain-following coordinates. Dyn. Atmos. Oceans, 32, 239-281.

Harrison, D. E., and N. K. Larkin, 1998: El Niño-Southern Oscillation sea surface temperature and wind anomalies. Rev. Geophys., 36, 353-399.

Higgins, R. W., V. E. Kousky, V. B. S. Silva, E. Becker, and P. Xie, 2010: Intercomparison of daily precipitation statistics over the United States in observations and in NCEP reanalysis products. J. Climate, 23, 4637-4650.

Hoffman, E. E., A. J. Busalacchi, and J. J. O'Brien, 1981: Wind generation of the Costa Rican Dome. Science, 214, 552-554.

Karnauskas, K. B., A. J. Busalacchi, and R. Murtugudde, 2008: Low-frequency variability and remote forcing of gap winds over the East Pacific warm pool. J. Climate, 21, 4901-4918.

Kessler, W. S., 1990: Observations of long Rossby waves in the northern tropical Pacific. J. Geophys. Res., 95, 5183-5217.

_ 2002: Mean three-dimensional circulation in the northeast tropical Pacific. J. Phys. Oceanogr., 32, 2457-2471.

- 2006: The circulation of the eastern tropical Pacific: A review. Prog. Oceanogr., 69, 181-217.

—, and J. P. McCreary, 1993: The annual wind-driven Rossby wave in the subthermocline equatorial Pacific. J. Phys. Oceanogr., 23, 1192-1207.

_ and M. J. McPhaden, 1995: Oceanic equatorial waves and the 1991-93 El Niño. J. Climate, 8, 1757-1774.

Killworth, P., D. B. Chelton, and R. A. de Szoeke, 1997: The speed of observed and theoretical long extratropical planetary waves. J. Phys. Oceanogr., 27, 1946-1966.

Large, W. G., J. C. McWilliams, and S. C. Doney, 1994: Oceanic vertical mixing-A review and a model with a nonlocal boundary-layer parameterization. Rev. Geophys., 32, 363-403.

Larkin, N. K., and D. E. Harrison, 2002: ENSO warm (El Niño) and cold (La Niña) event life cycles: Ocean surface anomaly patterns, their symmetries, asymmetries, and implications. J. Climate, 15, 1118-1140.

Liang, J. H., J. C. McWilliams, and N. Gruber, 2009: The highfrequency response of the ocean to mountain gap winds in the northeastern tropical Pacific. J. Geophys. Res., 114, C12005, doi:10.1029/2009JC005370.

McCreary, J. P., H. S. Lee, and D. B. Enfield, 1989: The response of the coastal ocean to strong offshore winds: With application to circulations in the Gulfs of Tehuantepec and Papagayo. J. Mar. Res., 47, 81-109.

McPhadden, M. J., and X. Zhang, 2009: Asymmetry in zonal phase propagation of ENSO sea surface temperature anomalies. Geophys. Res. Lett., 36, L13703, doi:10.1029/2009GL038774.

Okumura, Y. M., and C. Deser, 2010: Asymmetry in the duration of El Niño and La Niña. J. Climate, 23, 5826-5843.

Palacios, D. M., and S. J. Bograd, 2005: A census of Tehuantepec and Papagayo eddies in the northeastern tropical Pacific. Geophys. Res. Lett., 32, L23606, doi:10.1029/2005GL024324.

Rasmusson, E. M., and T. H. Carpenter, 1982: Variations in tropical sea surface temperature and surface wind fields associated with the Southern Oscillation/El Niño. Mon. Wea. Rev., 110, 354-384.

Rayner, N. A., D. E. Parker, E. B. Horton, C. K. Folland, L. V. Alexander, D. P. Rowell, E. C. Kent, and A. Kaplan, 2003: Global analyses of sea surface temperature, sea ice, and night marine air temperature since the late nineteenth century. J. Geophys. Res., 108, 4407, doi:10.1029/2002JD002670.

Reynolds, R. W., T. M. Smith, C. Liu, D. B. Chelton, K. S. Casey, and M. G. Schlax, 2007: Daily high-resolution blended analyses for sea surface temperature. J. Climate, 20, 5473-5496. 
Romero-Centeno, R., J. Zavala-Hidalgo, A. Gallegos, and J. J. O'Brien, 2003: Isthmus of Tehuantepec wind climatology and ENSO signal. J. Climate, 16, 2628-2639.

- — - and G. B. Raga, 2007: Midsummer gap winds and lowlevel circulation over the eastern tropical Pacific. J. Climate, 20, 3768-3784.

Rowe, G. D., E. Firing, and G. C. Johnson, 2000: Pacific equatorial subsurface countercurrent velocity, transport, and potential vorticity. J. Phys. Oceanogr., 30, 1172-1187.

Saha, S., and Coauthors, 2010: The NCEP Climate Forecast System Reanalysis. Bull. Amer. Meteor. Soc., 91, 1015-1057.

Schopf, P. S., D. L. T. Anderson, and R. Smith, 1981: Beta-dispersion of low frequency Rossby waves. Dyn. Atmos. Oceans, 5, 187-214.

Seager, R., M. B. Blumenthal, and Y. Kushnir, 1995: An advective atmospheric mixed-layer model for ocean modeling purposesGlobal simulation of surface heat fluxes. J. Climate, 8, 19511964.

Seo, H., A. J. Miller, and J. O. Roads, 2007: The Scripps Coupled Ocean-Atmosphere Regional (SCOAR) model, with applications in the eastern Pacific sector. J. Climate, 20, 381-402.

Shchepetkin, A. F., and J. C. McWilliams, 1998: Quasi-monotone advection scheme based on explicit locally adaptive dissipation. Mon. Wea. Rev., 126, 1541-1580.

—, and — , 2005: The regional oceanic modeling system (ROMS): A split-explicit, free-surface, topography-followingcoordinate ocean model. Ocean Modell., 9, 347-404.

Small, R. J., and Coauthors, 2008: Air-sea interaction over ocean fronts and eddies. Dyn. Atmos. Oceans, 45, 274-319.

Steenburgh, W. J., D. M. Schultz, and B. A. Colle, 1998: The structure and evolution of gap outflow over the Gulf of Tehuantepec, Mexico. Mon. Wea. Rev., 126, 2673-2691.
Strub, P. T., and C. James, 2002: The 1997-1998 El Niño signal along the SE and NE Pacific boundaries-An altimetric view. Prog. Oceanogr., 54 (1-4), 439-458.

Sun, F., and J.-Y. Yu, 2006: Impacts of Central America gap winds on the SST annual cycle in the eastern Pacific warm pool. Geophys. Res. Lett., 33, L06710, doi:10.1029/2005GL024700.

Umatani, S., and T. Yamagata, 1991: Response of the eastern tropical Pacific to meridional migration of the ITCZ: The generation of the Costa Rica Dome. J. Phys. Oceanogr., 21, 346-363.

White, W. B., 1977: Annual forcing of baroclinic long waves in the tropical North Pacific Ocean. J. Phys. Oceanogr., 7, 50-61.

Willett, C. S., R. Leben, and M. F. Lavín, 2006: Eddies and mesoscale processes in the eastern tropical Pacific: A review. Prog. Oceanogr., 69, 218-238.

Xie, S.-P., 2004: Satellite observations of cool ocean-atmosphere interaction. Bull. Amer. Meteor. Soc., 85, 195-208.

- H. Xu, W. S. Kessler, and M. Nonaka, 2005: Air-sea interaction over the eastern Pacific warm pool, gap winds, thermocline dome, and atmospheric convection. J. Climate, 18, 5-20.

Yu, L., and R. A. Weller, 2007: Objectively analyzed air-sea heat fluxes for the global ice-free oceans (1981-2005). Bull. Amer. Meteor. Soc., 88, 527-539.

Zamudio, L., A. P. Leonardi, S. D. Meyers, and J. J. O'Brien, 2001: ENSO and eddies on the southwest coast of Mexico. Geophys. Res. Lett., 28, 13-16.

- , H. E. Hurlburt, E. J. Metzger, S. L. Morey, J. J. O'Brien, C. E. Tilburg, and J. Zavala-Hidalgo, 2006: Interannual variability of Tehuantepec eddies. J. Geophys. Res., 111, C05001, doi:10.1029/2005JC003182.

Zhang, H.-M., J. J. Bates, and R. W. Reynolds, 2006: Assessment of composite global sampling: Sea surface wind speed. Geophys. Res. Lett., 33, L17714, doi:10.1029/2006GL027086. 